\title{
Chondrogenesis of human adipose-derived mesenchymal stromal cells on the [devitalized costal cartilage matrix/poly(vinyl alcohol)/fibrin] hybrid scaffolds
}

Citation for published version (APA):

Setayeshmehr, M., Esfandiari, E., Hashemibeni, B., Tavakoli, A. H., Rafienia, M., Samadikuchaksaraei, A., Moroni, L., \& Joghataei, M. T. (2019). Chondrogenesis of human adipose-derived mesenchymal stromal cells on the [devitalized costal cartilage matrix/poly(vinyl alcohol)/fibrin] hybrid scaffolds. European Polymer Journal, 118, 528-541. https://doi.org/10.1016/j.eurpolymj.2019.04.044

Document status and date:

Published: 01/09/2019

DOI:

10.1016/j.eurpolymj.2019.04.044

Document Version:

Publisher's PDF, also known as Version of record

Document license:

Taverne

Please check the document version of this publication:

- A submitted manuscript is the version of the article upon submission and before peer-review. There can be important differences between the submitted version and the official published version of record. People interested in the research are advised to contact the author for the final version of the publication, or visit the DOI to the publisher's website.

- The final author version and the galley proof are versions of the publication after peer review.

- The final published version features the final layout of the paper including the volume, issue and page numbers.

Link to publication

\footnotetext{
General rights rights.

- You may freely distribute the URL identifying the publication in the public portal. please follow below link for the End User Agreement:

www.umlib.nl/taverne-license

Take down policy

If you believe that this document breaches copyright please contact us at:

repository@maastrichtuniversity.nl

providing details and we will investigate your claim.
}

Copyright and moral rights for the publications made accessible in the public portal are retained by the authors and/or other copyright owners and it is a condition of accessing publications that users recognise and abide by the legal requirements associated with these

- Users may download and print one copy of any publication from the public portal for the purpose of private study or research.

- You may not further distribute the material or use it for any profit-making activity or commercial gain

If the publication is distributed under the terms of Article 25fa of the Dutch Copyright Act, indicated by the "Taverne" license above, 


\title{
Chondrogenesis of human adipose-derived mesenchymal stromal cells on the [devitalized costal cartilage matrix/poly(vinyl alcohol)/fibrin] hybrid scaffolds
}

\author{
Mohsen Setayeshmehr ${ }^{\mathrm{a}, \mathrm{b}}$, Ebrahim Esfandiari $^{\mathrm{c}}$, Batool Hashemibeni ${ }^{\mathrm{c}}$, Amir Hossein Tavakoli ${ }^{\mathrm{d}}$, \\ Mohammad Rafienia $^{\mathrm{e}}$, Ali Samadikuchaksaraei ${ }^{\mathrm{a}, \mathrm{f}}$, Lorenzo Moroni $^{\mathrm{b}}$, \\ Mohammad Taghi Joghataei ${ }^{\mathrm{a}, \mathrm{f}, *}$
}

${ }^{a}$ Department of Tissue Engineering \& Regenerative Medicine, Faculty of Advanced Technologies in Medicine, Iran University of Medical Sciences (IUMS), Tehran, Iran

${ }^{\mathrm{b}}$ MERLN Institute for Technology Inspired Regenerative Medicine, Complex Tissue Regeneration, Maastricht University, Maastricht, the Netherlands

${ }^{\mathrm{c}}$ Department of Anatomical Sciences, Faculty of Medicine, Isfahan University of Medical Sciences, Isfahan, Iran

${ }^{\mathrm{d}}$ Iranian Tissue Bank Research Center, Tehran University of Medical Sciences, Tehran, Iran

${ }^{\mathrm{e}}$ Biomaterials Nanotechnology and Tissue Engineering Group, Department of Advanced Medical Technology, Isfahan University of Medical Sciences, Isfahan, Iran

${ }^{\mathrm{f}}$ Cellular and Molecular Research Center, Iran University of Medical Sciences (IUMS), Tehran, Iran

\section{A R T I C L E I N F O}

\section{Keywords:}

Devitalized costal cartilage matrix

Poly vinyl alcohol

Genipin

Hybrid scaffold

Cartilage tissue engineering

\begin{abstract}
A B S T R A C T
Porous scaffolds derived from native cartilage matrix along with autologous cells could be an effective tool for cartilage tissue engineering (CTE). Recently, it was shown that scaffolds based on cartilage extra cellular matrix (ECM) can induce chondrogenesis of human adipose-derived mesenchymal stromal cells (ASCs) without using exogenous growth factors. However, lack of mechanical properties, rapid biodegradation, and contraction of these scaffolds in culture limit further applications. The present study investigated the fabrication of novel scaffolds based on devitalized costal cartilage matrix (DCM) and poly vinyl alcohol (PVA), using genipin as a natural crosslinker. For this purpose, PVA was modified to expose amine groups (PVA-A), which crosslinked with DCM powder via the lowest genipin percentage of $0.04 \%$ (wt/wt). The crosslinked scaffolds were characterized by different techniques including porosity percentage, pore size, mechanical properties, crosslinking density, and swelling. ASCs were seeded on the scaffolds using fibrin hydrogel. Gene expression measurements, biochemical assays and histological staining confirmed that ASC-seeded constructs cultured in the chondrogenic medium can express cartilage-specific genes and synthesize cartilage-related macromolecules. In the presence of TGF- $\beta 3$ the constructs exhibited significant expression of these markers compared to the control medium. These findings suggest that [genipin-crosslinked DCM-PVA-A/ fibrin] can be considered as an appealing hybrid scaffold for CTE applications.
\end{abstract}

\section{Introduction}

Articular cartilage has a limited self-repair capacity because of no vascularity and absence of progenitor cells. Traumatic damages and osteoarthritis are among the main reasons of articular cartilage degeneration [1-3]. The common clinical actions for healing of cartilage defects consist of microfracture, autologous chondrocyte transplantation, and allograft implants. However, none of these treatments achieves complete renewal of functional cartilage. Therefore, tissue engineering (TE) has been employed to promote cartilage regeneration using natural or synthetic scaffolds, stem cells, and growth factors $[4,5]$.

Polymeric materials to design hybrid and composite scaffolds in cartilage tissue engineering more frequently consist of poly(DL-lacticco-glycolic acid) (PLGA), poly(L-lactic acid) (PLA), poly( $\varepsilon$-caprolactone) (PCL), poly ethylene glycol (PEG), poly vinyl alcohol (PVA), and methacrylamide modification (MA) thereof [6]. Synthetic scaffolds are known to display adequate mechanical properties to match those of cartilage tissues, but their lack of appropriate biological cues reflect a main drawback [7]. PVA is one of the most studied polymers in

\footnotetext{
* Corresponding author at: Cellular and Molecular Research Center, Iran University of Medical Sciences (IUMS), Tehran, Iran.

E-mail addresses: m_setayeshmehr@med.mui.ac.ir (M. Setayeshmehr), esfandiari@med.mui.ac.ir (E. Esfandiari), hashemibeni@med.mui.ac.ir (B. Hashemibeni), m_rafienia@med.mui.ac.ir (M. Rafienia), samadikuchaksaraei@yahoo.com (A. Samadikuchaksaraei), l.moroni@maastrichtuniversity.nl (L. Moroni), mt.joghataei@yahoo.com, joghataei@iums.ac.ir (M.T. Joghataei).
} 
biomedical applications, because of its great biocompatibility in combination with a variety of appropriate biophysical properties. PVA has appropriate mechanical properties, swelling capacity, ability to fabricate a pore construction via chemical modifications and crosslinking opportunities [8]. The repeated freeze-thawing cycles, chemical crosslinking, dehydrothermal process and ultra violet (UV) irradiation are the mostly used crosslinking methods $[9,10]$. Despite these mentioned advantages, PVA has no appropriate integration ability with the surrounding natural tissue due to its lack of cell attachment binding sites [11]. However, different modifications have been shown on PVA hydrogels to promote biological properties such as cell proliferation, viability, migration, cell attachment and integration with the surrounding tissue [10].

Scaffolds derived from extracellular matrix (ECM) components induce cell attachment, proliferation and differentiation, but generally don't have proper mechanical properties and load bearing capacity [12]. The applications of cartilage ECM derivatives is growing in orthopedic medicine due to their chondroinduction ability [13]. The ability of cartilage ECM derivatives to preserve growth factors (GF)s is the key benefit of using this material as a scaffold [14]. Some studies have shown the ability of cartilage extract [15] and cartilage ECM to induce chondrogenesis in vivo and in vitro [16]. The native tissue is considered as one of the major types of ECM derivatives [17-19]. While autologous cartilage is a proper alternative for reconstructive procedures, challenges include donor site morbidity, quality, and availability. Alternatively, allograft costal cartilage can be considered as a proper cartilage source in these trials. Costal cartilage specimens are usually sterilized via gamma $(\gamma)$ irradiation to reduce the risk of infection transmission from the donor. Several clinical trials supported the successful use of irradiated allogeneic costal cartilage [20-23]. Decellularization and devitalization can be used to remove all cellular components or to disrupt cells within the tissue without eliminating them, respectively. Native cartilage is composed of a dense ECM that is a challenge to completely decellularize. This limits cell infiltration into the decellularized matrix $[1,12,18]$. In one devitalization method, the tissue is grounded into particles using a freezer-mill and then cellular components are inactivated by heating without removing them [24]. Freeze-thaw cycles and sonication also have been used for devitalization of cartilage [25]. Another technique consists of homogenization and tissue retrieval, followed by lyophilization of frozen particles [26].

To improve mechanical properties, ECM derived biomaterials can be mixed with synthetic biomaterials $[27,28]$, or crosslinked via physical methods including irradiation [29], dehydrothermal (DHT) treatment [30], and chemical crosslinkers such as carbodiimide [28] and genipin $[31,32]$. Each of these methods can achieve different crosslinking density and protein denaturation $[33,34]$, which effect scaffold contraction [28,35], cell infiltration and cell-matrix interactions [36], mechanical properties [36], and enzymatic degradation [37]. One of the common methods for crosslinking of proteins such as collagen and also some polymeric materials such as PVA is DHT treatment [33]. In these techniques, water molecules in polymer chains are removed by increasing temperature under reduced pressure. Nonetheless, denaturation of biological component such as collagen chains during heating process, that may induce immunogenicity, considered as a undesirable action in the DHT treatment [38-40]. UV irradiation has also been performed to crosslink PVA hydrogel [41] and also ECM based materials [26] to function as a vitreous implants or scaffolds for biomedical applications. To fabricate soft hydrogels, physical cross-linking of PVA has been also obtained by freezing and thawing cycles [10]. Genipin is a natural crosslinker with cytotoxicity about 10,000 times lower than glutaraldehyde [42]. Many studies explored the use of genipin in biomedical applications such as a crosslinker of TE scaffolds [43], to decrease immunogenicity of the scaffolds previous to implantation $[44,45]$, for its anti-inflammatory properties [46], and for controlled release of GFs [47]. The crosslinking mechanism of genipin is via linking it with primary amine groups of hydroxylysine or lysine residues on the polypeptide or proteoglycan chains, which results in the dark blue pigments formed in the matrix [48]. Some studies have confirmed that genipin crosslinked cartilage derived matrix (CDM) can prevent scaffolds contraction after cell seeding in conjunction with conservation of the chondrogenic induction capacity [49]. In spite of these confident benefits, genipin can inform some unwelcome effects on $\mathrm{CDM}$, as well as decrease in pore size and prevent cell infiltration, significant release of collagen and GAG macromolecules during crosslinking [50].

In this study, we present a novel hybrid scaffold based on devitalized costal cartilage matrix (DCM) from human ribs and PVA for CTE applications. Different physical and chemical crosslinking methods consisting of freeze-thaw cycles, UV irradiation, dehydrothermal treatment, and genipin were examined to conjugate these two natural and synthetic biomaterials. In a novel approach, to increase crosslinking efficiency and reduce crosslinker percentage, PVA was modified by more reactive amine functional groups. The crosslinked scaffolds were characterized by different techniques including porosity percentage, pore size, mechanical properties, crosslinking density, and swelling. An ASCs/fibrin suspension was seeded on the scaffolds to increase cell attachment and chondrogenic potential. The seeded constructs were cultured in the chondrogenic medium without/with TGF- $\beta 3$ to evaluate the chondrogenic potential of the fabricated scaffolds in comparison with fibrin hydrogel in micro-mass system.

\section{Materials and Methods}

\subsection{Tissue retrieval and devitalization}

Costal cartilages were harvested from the thorax of three organ donor cadavers (Emmam Khomeini hospital, Tehran, Iran) using scalpels [51,52]. The Institutional Ethics Committee of Iran University of Medical Sciences approved informed consent and the study. Cartilage was minced and then rinsed in $70 \%$ ethanol followed by phosphate buffered saline (PBS), and frozen at $-20{ }^{\circ} \mathrm{C}$. Following freezing, the cartilage was devitalized using freeze-thawing (3 cycles) and lyophililzing. Then, the tissue was powdered by a freezer-mill, refrozen, and stored at $-20^{\circ} \mathrm{C}$. Cartilage powder was sterilized using $\gamma$ radiation $25 \mathrm{G}$ prior using $[1,22]$.

\subsection{Scaffolds fabrication}

Porous hybrid scaffolds were fabricated by homogenizing different ratios of DCM powder to the PVA solutions at the final concentration of 0.1 gr dry wt/ml MiliQ water $\left(\mathrm{MH}_{2} \mathrm{O}\right)$ using vortexing $[26,49,50]$. Briefly, PVA $\left(72,000 \mathrm{MW}\right.$, Merk) was dissolved in $\mathrm{MH}_{2} \mathrm{O}$ at $90^{\circ} \mathrm{C}$ to prepare 3 different concentrations of PVA solution (3, 5, 7\% wt/vol) and the solutions were sterilized by $0.22 \mu \mathrm{m}$ filtration. Adequate amount of DCM was homogenized in each PVA solution for 3 cycles of $10 \mathrm{~min}$ ( $\mathrm{min}$ ) vortex at $30,000 \mathrm{rpm}$ and shaking overnight to prepare DCM-PVA slurries in three different ratios (30:70, 50:50, 70:30 DCM to PVA). Aliquots of homogenized DCM-PVA $(250 \mu \mathrm{l})$ were placed in silicon molds, frozen overnight at $-20^{\circ} \mathrm{C}$ and for $1 \mathrm{~h}(\mathrm{hr})$ at $-70{ }^{\circ} \mathrm{C}$, and consequently lyophilized for $24 \mathrm{hrs}$. Cylindrical porous scaffolds with $10 \mathrm{~mm}$ in diameter, $3 \mathrm{~mm}$ thick, and a dry weight of $25 \mathrm{mg}$ were prepared. The fabricated scaffolds consisted of 3 groups: 1) [non-crosslinked DCM-PVA (30:70)] (NCDP30), 2) [non-crosslinked DCM-PVA (50:50)] (NCDP50), and 3) [non-crosslinked DCM-PVA (70:30)] (NCDP70). Scaffolds were crosslinked by different methods, as below described. Finally, ultraviolet light (UV) radiation $30 \mathrm{~min}$ (min) was used to sterilize all scaffolds before cell culture.

\subsection{Crosslinking methods}

\subsubsection{Dehydrothermal treatment (DHT)}

The NCDP30, NCDP50, and NCDP70 scaffolds were placed inside a 
1)<smiles>CC(C)(C)CC(O)C(C)(C)C</smiles><smiles>CCOC(CCCN)OCC</smiles>

2)<smiles>CC(C)=O</smiles>
Genipin<smiles>CC(C)CC1CC(CC(C)(C)C)OC(CCCN)O1</smiles><smiles>CCC1CC(CC(C)O)OC(CCCN)O1</smiles><smiles>CCC1CC(CC(C)O)OC(CCCN)O1</smiles>

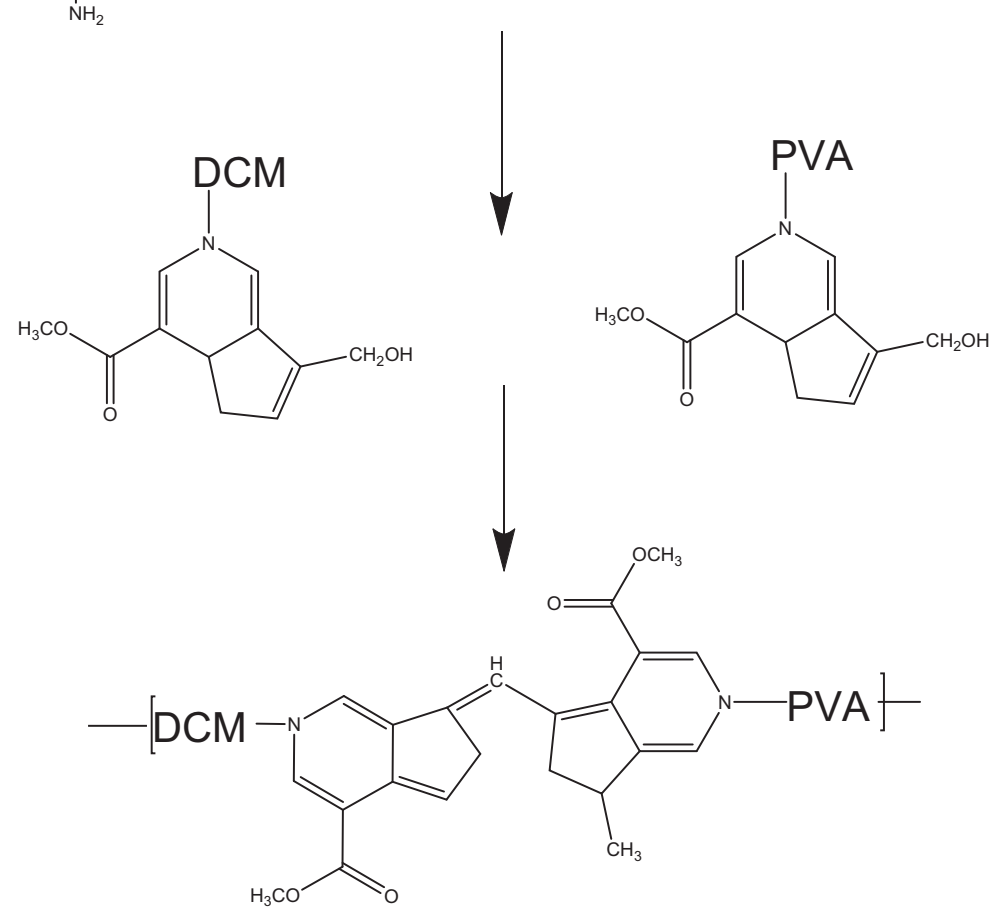<smiles>COC(=O)C1=COCC2C(CO)=CCC12</smiles>

Scheme 1. (1) Modification of PVA with amine groups.

(2) Crosslinking reaction of PVA-A and DCM with genipin.

vacuum oven (Vacucell 22, MMM, Germany) under $120^{\circ} \mathrm{C}$ heating and 0.05 bar vacuum for $24 \mathrm{hrs}$. The crosslinking degree of DHT treatment of the DCM-PVA scaffolds was determined using a solubility test in PBS [33].

\subsubsection{UV treatment}

The NCDP30, NCDP50, and NCDP70 scaffolds were placed inside a UV cabinet ( $400 \mathrm{~W}, 265 \mathrm{~nm}$, Iran) under exposure of UV light for $24 \mathrm{hrs}$ [50].

\subsubsection{Freeze-thaw cycles}

The silicon molds containing homogenized DCM-PVA slurry (30:70, 50:50, 70:30 DCM to PVA) were frozen to $-25^{\circ} \mathrm{C}$ for $20 \mathrm{hrs}$ and then thawed at $30^{\circ} \mathrm{C}$ for $4 \mathrm{hrs}$. This freeze-thaw cycles was repeated 30 other times, and consequently lyophilized for $24 \mathrm{~h}$ [53].

\subsubsection{Chamical crosslinking with genipin}

2.3.4.1. PVA modification. PVA was modified with primary amine functional groups (Scheme 1) via a method previously described [54].
Briefly, PVA was dissolved in $\mathrm{MH}_{2} \mathrm{O}$ at $90^{\circ} \mathrm{C}$ to prepare a $12 \%$ wt/vol solution. An equal volume of $10 \mathrm{~mol} \%$ 4-aminobutyraldehyde diethyl acetal (4-ABA) (sigma) was calculated and added dropwise to the solution. The $\mathrm{pH}$ was decreased close to zero by adding dropwise $\mathrm{HCl}$ $12 \mathrm{M}$ to the solution, and the solution was mixed for $1 \mathrm{~h}$. Then, the $\mathrm{pH}$ was increased to 8.0 with the addition of adequate amount of $\mathrm{NH}_{4} \mathrm{OH}$. The prepared solution was purified by dialysis tubing (MWCO 2000, sigma) in deionized water and finally lyophilized. ${ }^{1} \mathrm{H}$ nuclear magnetic resonance spectroscopy ( ${ }^{1} \mathrm{H}$ NMR) was used to confirm the modification of the PVA by 4-ABA groups. For this issue, samples were dissolved in $\mathrm{D}_{2} \mathrm{O}$ and the spectra was acquired using a Bruker 700 spectrometer [54].

2.3.4.2. Genipin crosslinking. PVA and PVA-amine (PVA-A) were dissolved in $\mathrm{MH}_{2} \mathrm{O}$ at $90^{\circ} \mathrm{C}$. Three different DCM-PVA slurry ratios (30:70, 50:50, 70:30) were prepared similar to previous sections. Then, adequate amount of genipin (Santacruz, sc-203057A) solution $(0.04 \%$ dry weight of genipin/dry weight of sample) in ethanol $(10 \mathrm{mg} / \mathrm{ml})$ was added to the slurry and homogenized again. Aliquots of homogenized 
slurry $(250 \mu \mathrm{l})$ were placed in silicon molds and subsequently crosslinked in shaker incubator at $37^{\circ} \mathrm{C}$ for 3 days, then, frozen overnight at $-20^{\circ} \mathrm{C}$ and for $1 \mathrm{~h}$ at $-70^{\circ} \mathrm{C}$, and lyophilized for $24 \mathrm{hrs}$ [49]. Finally, 3 groups consisting of [genipin-crosslinked DCM-PVA-A (30:70)] (GCDPA30), [genipin-crosslinked DCM-PVA-A (50:50)] (GCDPA50), and [genipin-crosslinked DCM-PVA-A (70:30)] (GCDPA70) scaffolds were prepared (Scheme 1).

\subsection{Porosity measurement}

The porosity of the scaffolds was determined using liquid displacement via method previously described [49]. Briefly, a scaffold was moved into a graduated cylindrical container that was filled with a known volume of hexane $\left(\mathrm{V}_{1}\right)$. The increasing of hexane volume as a consequence of putting the scaffold in the container was measured as $\left(V_{2}\right)$. The scaffold was removed after impregnation with hexane during $5 \mathrm{~min}$, and the remaining volume in the container was measured $\left(\mathrm{V}_{3}\right)$. The porosity percentage was calculated via the following formula: porosity percentage $=100 \times\left(V_{1}-V_{3}\right) /\left(V_{2}-V_{3}\right)$, where $\left(V_{1}-V_{3}\right)$ is the volume of pores in the scaffold, and $\left(V_{2}-V_{3}\right)$ is the total volume of the scaffold.

\subsection{Water uptake and weight loss}

The scaffolds ( $\mathrm{n}=3$ ) were placed in PBS in a container at $37{ }^{\circ} \mathrm{C}$ and $95 \%$ humidity until the weight of the hydrated scaffolds stopped to increase, by checking the weight of scaffolds at different times. Where $\mathrm{W}_{\mathrm{d}}$ is the weight of dried scaffold, and $\mathrm{W}_{\mathrm{h}}$ is the weight of hydrated scaffold, then the water uptake percentage was obtained via following formula: $100 \times\left(\mathrm{W}_{\mathrm{h}}-\mathrm{W}_{\mathrm{d}}\right) / \mathrm{W}_{\mathrm{d}}$. [55]. The weight loss of the constructs at the end of each time point (a week) was determined using the equation: $100 \times\left(\mathrm{W}_{\mathrm{i}}-\mathrm{W}_{\mathrm{f}}\right) / \mathrm{W}_{\mathrm{i}}$, where (wi) is the initial weight of dry sample and (wf) is weight of the final dry sample. The scaffolds washed with deionized water to eliminate any PBS salt and weighed after vacuum drying at RT to calculate the percentage of the weight loss [56]. The average value of three samples was reported as the water uptake and weight loss.

\subsection{Crosslinking degree}

Fourier transform infrared (FT-IR) spectroscopy was carried out to determine the amount of crosslinking density [33]. FT-IR spectra of NCDPA70 and GCDPA70 scaffolds were obtained using the FT-IR spectrophotometer (Jasco 680 plus spectrometer, Japan). Cylindrical $\mathrm{KBr}$ pellets were fabricated by mixing $1 \mathrm{mg}$ of the sample powder and $200 \mathrm{mg}$ of $\mathrm{KBr}$ salt [57]. The decrease in the absorbance peaks around $1600 \mathrm{~cm}^{-1}$ or around $800 \mathrm{~cm}^{-1}$ was employed to detect the presence of amine groups in the NCDPA70 and GCDPA70 scaffolds to determine the degree of crosslinking of the materials. [58]. These peaks were normalized with the absorbance at $2931 \mathrm{~cm}^{-1}$ (C-H bond), which is unaffected during formation of amide bonds. The inverse of the ratio of $(1600 / 2931$ and 800/2931) were calculated to determine the amount of crosslink density. The degree of crosslinking was defined as the percentage of reacted amines after genipin reaction relative to the free amines in the non-crosslinked scaffold [38,59].

Ninhydrin assay was also performed to determine the amount of amine groups in the NCDPA70 and GCDPA70 samples to achieve crosslink density of the scaffolds. The purple pigment produced after the reaction of ninhydrin reagent (Sigma) with free amine groups in the porous scaffolds was detected via a UV-Visible spectrophotometer at a $560 \mathrm{~nm}$ wavelength. The crosslinking density was calculated as the percentage of reacted amines after crosslinking relative to the free amines in the non-crosslinked scaffold [26].

\subsection{Scanning electron microscopy}

NCDPA70 and GCDPA70 scaffolds were sputter coated with gold. The microstructure of the scaffolds was observed with scanning electron microscope (SEM, Zeiss, Germany). The pore sizes of scaffolds were measured by drawing the boundary of the pores using Image $\mathrm{J}$ software (Fiji-win 64). The area covering 15 pores was evaluated for each scaffold [49].

\subsection{Mechanical property of scaffolds}

Young's modulus was measured via compression test using a mechanical testing machine (Santam, Iran) to explore the mechanical properties of GCDPA70 hybrid scaffolds according to a method previously described [60]. The cylindrical scaffolds $(n=3)$ with dimension $10 \times 3 \mathrm{~mm}$ were compressed at a constant speed of $1.0 \mathrm{~mm} / \mathrm{min}$. The results from the stress-strain curves were used to determine the Young's modulus of each sample.

\subsection{Isolation and culture of ASCs}

The ASCs were obtained from liposuction waste of subcutaneous adipose tissue from the 4 female donors (Al Zahra Hospital, Isfahan University of Medical Sciences) with age of 25-45 and an average body-mass index of 25-30. The Institutional Ethics Committee of Iran University of Medical Sciences approved informed consent and the study. Collagenase type IA was used to digest adipose tissue at $37^{\circ} \mathrm{C}$ for $30 \mathrm{~min}$ according to previous work $[61,62]$. The cells were cultured on $75-\mathrm{cm}^{2}$ culture flasks at a starting density of 6000 cells $/ \mathrm{cm}^{2}$ in expansion medium consisting of the Dulbecco's modified Eagle's medium (DMEM, BI1025, Bioidea, Iran), 10\% fetal bovine serum (FBS; Gibco10270), 1\% penicillin-streptomycin (1025, Bioidea, Iran), and $10 \mathrm{ng} /$ $\mathrm{mL}$ basic fibroblast growth factor (b-FGF, RP-1112, Royan, Iran). The cells were cultured at $37{ }^{\circ} \mathrm{C}$ in $5 \% \mathrm{CO}_{2}$, and medium changed every $48 \mathrm{~h}$. After reaching $90 \%$ confluence, the cells were harvested using $0.05 \%$ trypsin- EDTA (Bioidea, Iran) and counted to seed on the scaffolds $[49,63,64]$.

\subsection{Preparations of fibrin hydrogel}

Human fresh-frozen plasma (FFP) and cryoprecipitate were acquired from the Blood Donation Center (Isfahan, Iran) as starting materials. Thrombin solution was extracted by adding $400 \mathrm{mM} \mathrm{CaCl}_{2}$ to FFP $(1: 9 \mathrm{vol} / \mathrm{vol})$, then the clots incubated in $37^{\circ} \mathrm{C}$ for $90 \mathrm{~min}$, and centrifuged at $2200 \mathrm{rpm}$ at $4{ }^{\circ} \mathrm{C}$ for $10 \mathrm{~min}$ to obtain thrombin concentrate. Following thawing, the cryoprecipitate was used as the fibrinogen component $[61,65,66]$.

\subsection{Proliferation, morphology and differentiation of ASCs on scaffolds}

ASCs were resuspended in thrombin (cell density, $2 \times 10^{7}$ cells $/ \mathrm{ml}$ ) and seeded onto GCDPA70 scaffolds $\left(1 \times 10^{6}\right.$ cells/scaffold $)$ by pipetting. Cells were allowed to infiltrate and attach to the scaffolds for $1 \mathrm{~h}$ at $37^{\circ} \mathrm{C}$ prior to the addition of fibrinogen to the scaffolds. Cell-scaffold constructs were further incubated in the medium at $37^{\circ} \mathrm{C}$ in an atmosphere of 5\% CO2 and 95\% humidity and the medium changed every 48 hrs. Cell viability and proliferation within the scaffolds were analyzed by 3-(4,5-Dimethyl-2-thiazolyl)-2,5-diphenyl-2H-tetrazolium bromide (MTT, Sigma) assay at day 1, 3, and 7 of the culture according to previous works [61].

Morphological characteristics and the distribution of the cells within scaffolds were analyzed by SEM analysis. The cell seeded [GCDPA70/ fibrin] hybrid constructs were washed with PBS and fixed overnight in $3 \%$ glutaraldehyde at $4{ }^{\circ} \mathrm{C}$. Different concentrations ethanol was used to dehydrate the samples, then the samples were dried and analyzed with a SEM $[60,67]$. 
Table 1

The composition and abbreviation of the different culture groups in the current study.

\begin{tabular}{|c|c|c|c|}
\hline Group & Composition & Time (day) & Abbreviation \\
\hline Fibrin/Micro-mass culture & cell + fibrin + control medium & 28 & $\mathrm{~F}-28$ \\
\hline Fibrin-TGF- $\beta 3$ /Micro-mass culture & cell + fibrin + TGF- $\beta 3$ medium & 28 & F-TGF-28 \\
\hline Cell free [GCDPA70/ fibrin] & scaffold + control medium & 14,28 & CF-14, CF-28 \\
\hline [GCDPA70/ fibrin] & cells + scaffold + control medium & 14,28 & CRL-14, CRL-28 \\
\hline [GCDPA70/ fibrin]-TGF- $\beta 3$ & cells + scaffold + TGF- $\beta 3$ medium & 14,28 & TGF-14, TGF-28 \\
\hline
\end{tabular}

[GCDPA70/Fibrin] constructs were cultured for 14 and 28 days (Table 1) in the $2 \mathrm{ml}$ of the culture medium (control medium, CRL) composed of DMEM high-glucose (Bioidea BI1025), 1\% penicillin-streptomycin (Bioidea-1025), L-ascorbic acid 2-phosphate $(37.5 \mathrm{mg} / \mathrm{ml}$; Sigma-A8960-5G), 1\% ITS + Premix (Gibco-41400-45), and $10 \mathrm{nM}$ dexamethasone (Sigma-D4902-100MG) (Table 1). In addition, the scaffolds were cultured for 14 and 28 days in the culture medium (TGF medium) containing $10 \mathrm{ng} / \mathrm{ml}$ TGF- $\beta 3$ (Sigma-T-9705) to investigate chondrogenesis of the ASCs. The same volume of the cell/fibrin hydrogel seeded on the hybrid constructs were cultured in the well-known micro-mass system (Table 1), in CRL and TGF medium to investigate the chondroinductivity of the [GCDPA70/Fibrin] hybrid constructs compared to the fibrin hydrogel [62]. The fibrin hydrogels and hybrid constructs were subsequently cultured in the $\mathrm{CO}_{2}$ incubator at $37^{\circ} \mathrm{C}$, the media changed every 2 days, and cultures were dismissed at day 14 and 28 for further evaluation $[61,66,68]$.

\subsection{Real-time polymerase chain reaction (RT-PCR)}

Three fresh constructs were moved into $1.5 \mathrm{ml}$ plastic vials and then snap-frozen, crushed, and lysed using super RNA Extraction Kit for Tissue and Cells (YT9080, YTA, Iran). Then, total RNA was extracted by the purification system based on the manufacturer's optional procedure. After RNA extraction, the high-capacity cDNA Synthesis Kit (YT4500, YTA, Iran) was used to synthesize single-stranded cDNA. Real-time PCR Step One Plus real-time PCR system (Applied Biosystem) with primers that were designed by Allele ID 7.6 software according to our previous works, was used to compare the transcript levels for 3 different genes: aggrecan (ACAN, FWD: GTGGGACTGAAGTTCTTG, REW: GTTGTCATGGTCTGAAGTT), types II collagen (COLIIA1, FWD: CTGGTGATGATGGTGAAG, REV: CCTGGATAACCTCTGTGA) and types X collagen: (COLX, FWD: AGAATCCATCTGAGAATATGC, REW: CCTC TTACTGCTATACCTTTAC). Relative gene expression was measured using 2X Real-Time PCR Master Mix, High ROX SYBR ${ }^{\circledR}$ Green1 (BioFACT). The glyceraldehyde 3-phosphate dehydrogenase ( $\beta$-Actin, FWD: GTTGTCGACGACGAGCG, REV: GCACAGAGCCTCGCCTT) primer was considered as the internal control. Comparative $\mathrm{Ct}(\Delta \Delta \mathrm{Ct})$ was used for calculation of the relative gene expression. [53,61]

\subsection{Biochemical analysis}

\subsubsection{DNA quantification}

Papain solution ( $1 \mathrm{ml}$ per each sample, $50 \mathrm{U} / \mathrm{ml}$ papain, in PBS pH 6, containing $5.5 \mathrm{mM}$ EDTA and L-cysteine hydrochloride $125 \mathrm{mM}$, all materials from Sigma) were used to digest ( $n=3$ for each sample) at $65^{\circ} \mathrm{C}$ for $24 \mathrm{~h}$. The DNA quantitation kit, fluorescence assay (DNAQF Sigma-Aldrich) containing Hoechst 33,258, calf thymus DNA standard, and 10X Assay Buffer, was used to quantify DNA content of samples according to the manufacturer's instructions. Standard ascendant concentrations DNA of the calf thymus and papain digested samples including lyophilized natural cartilage (CAR), devitalized costal cartilage matrix (DCM), crosslinked cell free scaffold (CF) and cultured constructs in Day 1, 14, and 28 was quantified using a spectrofluorophotometer (BioTek FL600) at $360 \mathrm{~nm}$ excitation and $460 \mathrm{~nm}$ emission. After drawing the standard curve, DNA concentration of each unknown sample was obtained by interpolation of its absorbance from the standard curve, and DNA content was reported in ng/mg of dry weight of samples [50].

\subsubsection{Sulphated glycosaminoglycans (GAG)s quantification}

GAG content was measured by following the method previously described on the papain digested samples $[69,70]$. Briefly, standard ascendant concentrations of bovine chondroitin sulphate (Sigma) were prepared. In a transparent 96-well plate, $250 \mu \mathrm{l}$ 1,9-dimethylmethylene blue solution (DMMB, Sigma) was added to each plate containing standards and samples $(40 \mu \mathrm{l})$, the plate was shacked for $2 \mathrm{~min}$ before reading absorbance by Spectrophotometric multi well plate reader (Hyperion MPR4) at $540 \mathrm{~nm}$. After the drawing standard curve, GAG concentration of each unknown sample was obtained by interpolation of its absorbance from the standard curve, and finally was reported in weight of GAG/ weight of DNA ( $\mu \mathrm{g} / \mathrm{mg}$ ) for each samples.

\subsubsection{Collagen quantification}

The hydroxyproline assay kit (MAK008 Sigma-Aldrich) was used to quantify hydroxyproline content of samples according to the manufacturers' instructions. $100 \mu \mathrm{l} \mathrm{HCl} 12 \mathrm{M}$ (sigma) were used to digest $10 \mathrm{mg}$ of lyophilized samples ( $\mathrm{n}=3$ for each group) at $120^{\circ} \mathrm{C}$ for $3 \mathrm{~h}$ $[69,71] .0,2,4,6,8$, and $10 \mu \mathrm{l}$ of the $0.1 \mathrm{mg} / \mathrm{mL}$ hydroxyproline standard solution was added into a 96 well plate. In addition, $10 \mu \mathrm{l}$ of each digested unknown samples were transferred to a well. All wells consisting of standards and unknown samples were evaporated and dried. $100 \mu \mathrm{l}$ of the Chloramine T/Oxidation buffer mixture were added to each wells. The plate was incubated at room temperature for $5 \mathrm{~min}$. $100 \mu$ of the diluted DMAB reagent were added to each well, and incubated for $90 \mathrm{~min}$ at $60^{\circ} \mathrm{C}$. Finally, the absorbance was measured by spectrophotometric multi well plate reader (Hyperion MPR4) at $540 \mathrm{~nm}$. After drawing the standard curve, hydroxyproline concentration of each unknown sample was obtained by interpolation of its absorbance from the standard curve. Finally, hydroxyproline contents were reported in $\mathrm{mg}$ hydroxyproline per $10 \mathrm{mg}$ of samples.

\subsection{Histological analyses}

Constructs were fixed $24 \mathrm{~h}$ at $4{ }^{\circ} \mathrm{C}$ in $10 \%$ buffered formalin in PBS solution. Constructs were processed by increasing ethanol solutions before cleared by xylene series. Then, the samples were embedded in paraffin and cut into $5 \mu \mathrm{m}$ slices. Xylene-cleared sections were stained using general histological staining, Hematoxylin and Eosin (H\&E). For staining of GAGs, Toluidine blue staining $(0.125 \%, 20 \mathrm{sec})$ was performed, and also xylene-cleared sections were treated with hematoxylin for $5 \mathrm{~min}, 0.02 \%$ fast green for $1 \mathrm{~min}, 1 \%$ aqueous safranin-O solution for $30 \mathrm{~min}$, rinsed with distilled water, and dehydrated and cleared and mounted on microscope slides $[49,67]$.

Immunohistochemical staining was also performed on $5-\mu \mathrm{m}$ sections using monoclonal antibodies to type II collagen (ab3092; Abcam). For antigen retrieval the slides incubated in hyaluronidase $8 \mathrm{mg} / \mathrm{ml}$ (Sigma) for $3 \mathrm{~h}$ at $37^{\circ} \mathrm{C}$. The nonspecific binding sites were blocked using blocking buffer and slides were incubated with primary antibodies at $4{ }^{\circ} \mathrm{C}$ over-night. Then, after washing, slides were labeled with secondary antibody (anti-mouse IgG, ab2891; Abcam) conjugated with horseradish peroxidase and then established using 3,3'- diaminobenzene substrate (DAB kit, ab94656; Abcam). The cell free scaffold was 

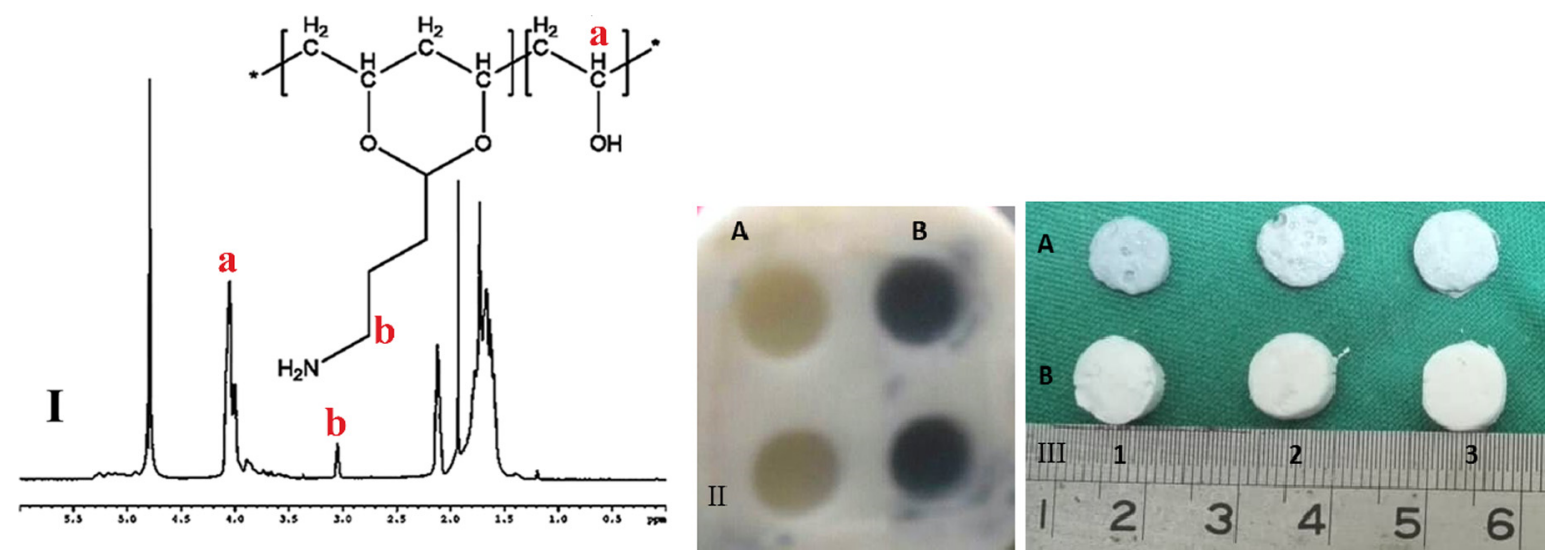

Fig. 1. I: ${ }^{1} \mathrm{H}$ NMR spectrum of aminated PVA, Successful backbone modification was verified by amine peak at 3 ppm. II: Genipin crosslinking of PVA and PVA-A with DCM; (A): DCM/PVA wasn't able to crosslink in combination with 0.04\% ganipin, while (B): DCM/PVA-A crosslinked easily in the same condition. III: Volume change of (A): genipin-crosslinked and (B): non-crosslinked DCM/PVA-A scaffolds. Gross photographs of left to right: 30\%, 50\%, and 70\% DCM containing scaffolds.

considered as proper positive controls for antibody to confirm antibody specificity $[50,61]$.

\subsection{Statistical analysis}

For the statistical analysis, data were evaluated using the Kolmogorov-Simonov test for normal distribution analysis of variables and (one-way analysis of variance) post-hoc test was employed to determine significance between different groups and different time points $(\alpha=0.05)$ of the MTT, ELISA and RT-PCR results.

\section{Results}

\subsection{PVA amination}

The ${ }^{1} \mathrm{H}$ NMR spectrum for aminated PVA is shown in Fig. 1-I. PVA was modified with $10 \%$ target amination. Peaks at chemical shifts of 3 ppm confirmed successful amination. The efficiency (36\%) and amination percentage (4.25\% per hydroxyl groups of polymer chains) was calculated from the ratio of amine peak to the $-\mathrm{CH}$ peak in the spectra.

\subsection{Scaffolds fabrication}

The results of solubility test (Table 2) showed that the scaffolds cross-linked via freeze-thaw cycles, UV irradiation, dehydrothermal treatment, also using $0.04 \%$ (wt/wt) genipin were soluble in PBS. These methods were not efficient enough to crosslink PVA and DCM to make stable structures. Otherwise, amine modification of the PVA increased polymer reactivity, and PVA-A and DCM crosslinked efficiently (Fig. 1II) after $72 \mathrm{~h}$ at $37^{\circ} \mathrm{C}$, while crosslinking of unmodified PVA and DCM was not efficient at the same condition. The results of the gross morphology (Fig. 1- III) and porosity measurement (Table 2) showed significant shrinkage and decrease in the porosity of the GCDPA30 and GCDPA50 scaffolds composed of 30\% and 50\% DCM respectively, compared to the GCDPA70 scaffolds composed of 70\% (wt/wt) DCM (Fig. 1-III). Therefore, GCDPA70 scaffolds were chosen as the appropriate scaffolds for following characterizations and cell studies, while GCDPA30 and GCDPA50 were excluded from the study.

\subsection{Water uptake}

It is necessary to highlight the effect of DCM on the degradation performance of the hybrid scaffolds, as biodegradation is a critical

Table 2

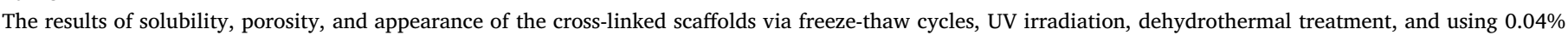

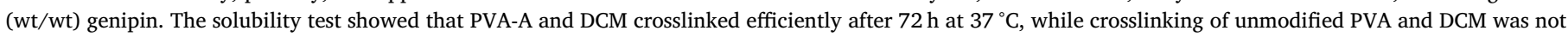
efficient at the same condition using 0.04\% (wt/wt) genipin $(n=3)$.

\begin{tabular}{|c|c|c|c|c|}
\hline Crosslinking method & DCM content (\%) & Color and appearance & Dissolution time (hrs) & Porosity $\%$ \\
\hline \multirow[t]{3}{*}{ Non crosslinked scaffolds } & 30 & white- rectangular & 2 & $82 \pm 2.5$ \\
\hline & 50 & white- rectangular & 2 & $87 \pm 2.1$ \\
\hline & 70 & white- rectangular & 2 & $92 \pm 3$ \\
\hline \multirow[t]{3}{*}{ Freeze-thaw cycles } & 30 & white- shrunk & 24 & - \\
\hline & 50 & white- shrunk & 24 & - \\
\hline & 70 & white- shrunk & 24 & - \\
\hline \multirow[t]{3}{*}{ Dehydrothermal treatment } & 30 & white- rectangular & 72 & $81 \pm 4.5$ \\
\hline & 50 & white- rectangular & 72 & $85 \pm 3.2$ \\
\hline & 70 & white- rectangular & 72 & $93 \pm 5.1$ \\
\hline \multirow[t]{3}{*}{ UV- irradiation } & 30 & yellowish- rectangular & 24 & - \\
\hline & 50 & yellowish- rectangular & 24 & - \\
\hline & 70 & yellowish- rectangular & 24 & - \\
\hline \multirow[t]{3}{*}{ Genipin-crosslinked DCM/PVA } & 30 & Pale blue-rectangular & 48 & - \\
\hline & 50 & Pale blue-rectangular & 48 & - \\
\hline & 70 & Pale blue-rectangular & 48 & - \\
\hline \multirow[t]{3}{*}{ Genipin-crosslinked DCM/PVA-A } & 30 & dark blue- shrunk & insoluble & $45 \pm 6$ \\
\hline & 50 & dark blue- shrunk & insoluble & $71 \pm 5.1$ \\
\hline & 70 & dark blue- rectangular & insoluble & $89 \pm 3$ \\
\hline
\end{tabular}




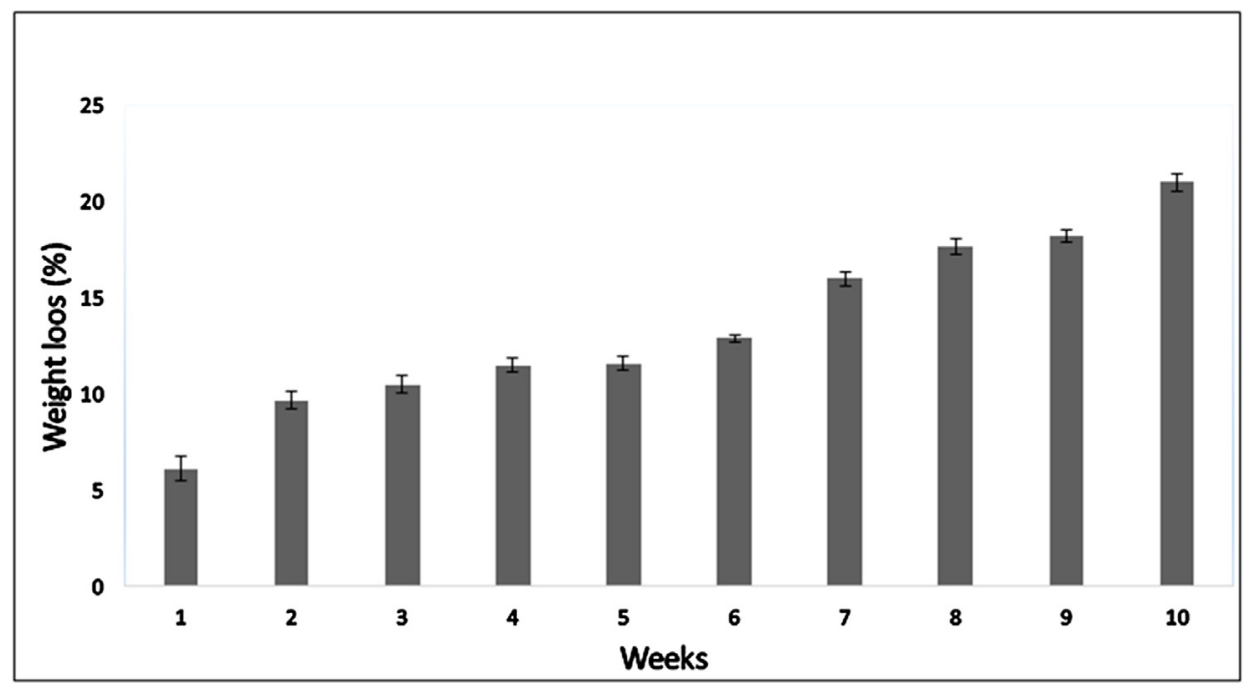

Fig. 2. Weight loss $\%$ vs. incubation time in PBS for GCDPA70 scaffolds.

factor to evaluate the regeneration of the injured cartilage. Hence, water uptake is principally considered as an important factor for the degradation of the scaffold. Water uptake and biodegradation tests carried out just for GCDPA70 scaffolds, since other scaffolds were excluded from the study as earlier explained. The results of water uptake test showed that the water absorption capacity of the GCDPA70 scaffolds was $504 \pm 26.7 \%(n=3)$. Therefore, the construct can absorb culture medium and support proper nutrient infiltration. The weight loss for the GCDPA70 scaffolds after incubation in PBS is shown in Fig. 2. The results showed that the weight loss of the scaffolds was gradual during the degradation period. After a week of incubation, the scaffolds lost about $6.1 \pm 0.65 \%$ of its initial weight, followed by a gentle weight loss during the remaining weeks. As a result, $20.99 \pm 0.44 \%$ of the original weight was lost after 10 weeks of incubation.

\subsection{Crosslinking degree}

FT-IR spectroscopy carried out just for GCDPA70 scaffolds and other scaffolds were excluded from the study. The crosslink density of the GCDPA70 scaffold was calculated from FT-IR spectrum and is shown in Fig. 3. The calculated crosslinking density was $50.7 \pm 15.5 \%(n=3)$. Also, ninhydrin assay results indicated that the crosslinking degree of genipin crosslinked scaffolds was up to $63.19 \pm 9.9 \%(n=3)$.

\subsection{Scanning electron microscopic}

The SEM micrographs of the NCDPA70 (Fig. 4-A) and GCDPA70 scaffolds (Fig. 4-B) showed pore size between 37 and 122 and $22-95 \mu \mathrm{m}$, and the average pore diameter was $67 \pm 22$ and $57 \pm 21 \mu \mathrm{m}$, respectively. The macroporous structure with interconnected and well-arranged pores was generated within the scaffold. After $24 \mathrm{~h}$ of culture, SEM analyses showed that ASCs attached efficiently on the (GCDPA70/fibrin) hybrid constructs and started to secreted ECM (Fig. 4-C).

\subsection{Mechanical properties}

The results of the Force-Extension curve of the GCDPA70 constructs were demonstrated that elastic modulus of the scaffolds and elongation at break have been found to be $14.7 \pm 2.7 \mathrm{kPa}$ and $62.39 \pm 6.56 \%$ respectively $(n=3)$.

\subsection{MTT assay}

The results of MTT assay at days 1, 3 and 7 showed the viability of the ASCs in the (GCDPA70/Fibrin) hybrid constructs compared to 2D culture as the control (Fig. 5). The analysis showed a significant proliferation of ASCs on the developed scaffolds at day 3 and day 7

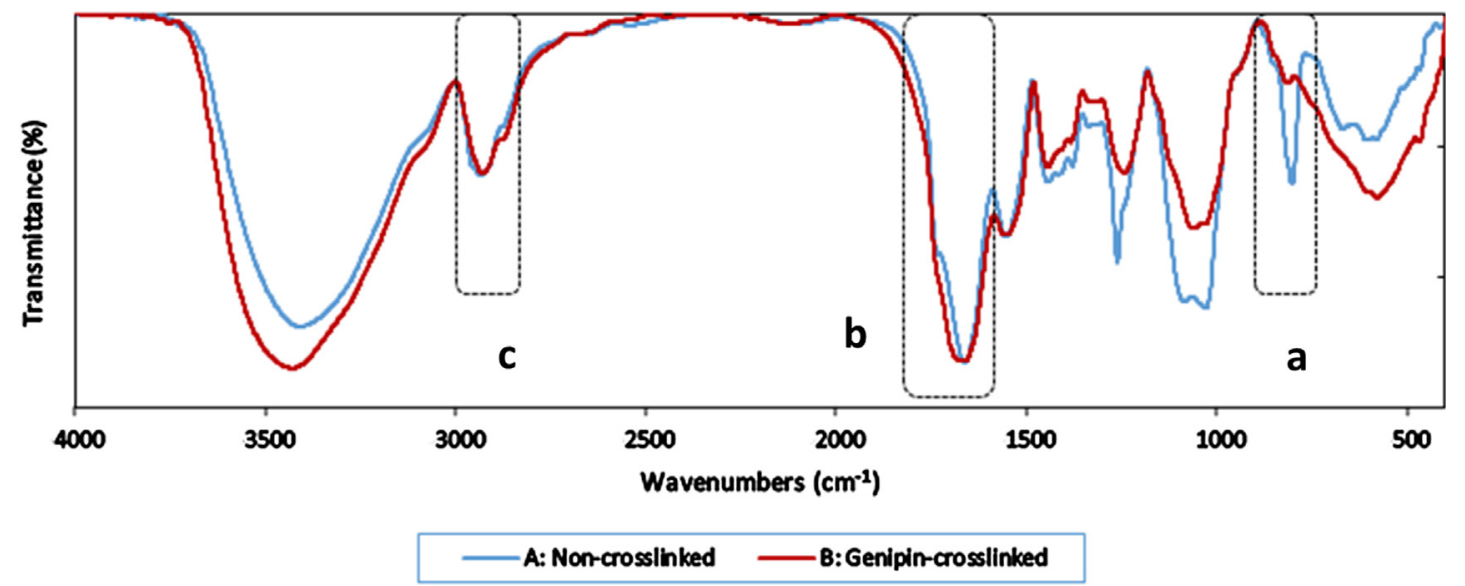

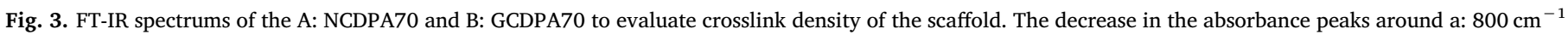

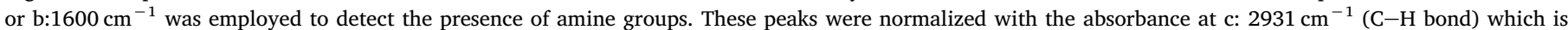
unaffected during formation of amide bonds $(n=3)$. 

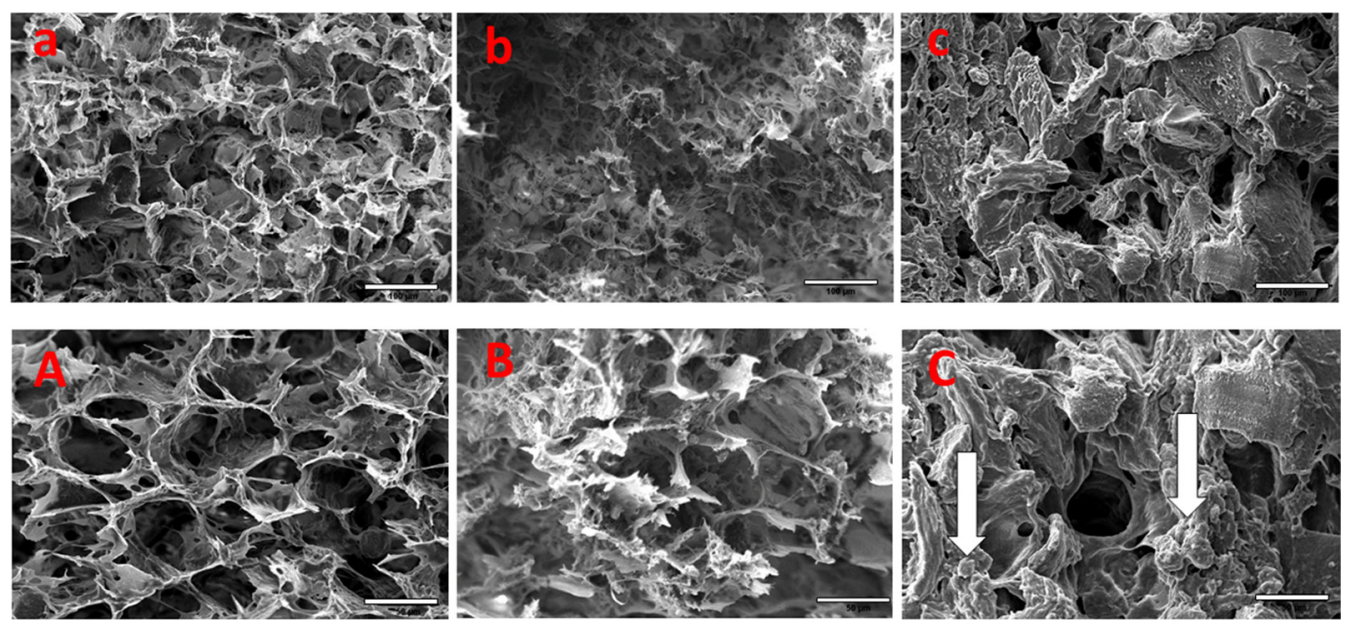

Fig. 4. Scanning electron micrographs of A: NCDPA70, B: GCDPA70scaffolds, and C: cell seeded [GCDPA70/Fibrin] hybrid constructs (scale bars a, b, $\mathrm{c}=100$ and A, $\mathrm{B}, \mathrm{C}=50 \mu \mathrm{m})$.

compared to day 1. Yet, ASCs metabolic activity in 2D cell cultures was approximately 2 times higher than in (GCDPA70/Fibrin) constructs.

\subsection{Gene expression}

The two chondrogenesis gene markers, ACAN, COLIIA1, and the hypertrophic gene marker COLX were analyzed in control, and TGF groups for [GCDPA70/Fibrin] constructs at day 14 and 28, and fibrin hydrogel cultured in micro mass system at day 28 (Fig. 6). In control medium, the two positive chondrogenic markers were significantly upregulated by the hybrid scaffolds. COLIIA1 was significantly increased relative to day 1 , which exhibited approximately 12 -fold through day 14. A 60-fold increase was also observed until day 28. ACAN transcript values were also significantly upregulated 3-fold over the first 14 days, to 6-fold by day 28 . Also, a significant upregulation of COLX was observed. By day 14, COLX levels had increased approximately 6.6 -fold relative to day 1 . A slight trend showing an increase in COLX production was noted through day 28 , which showed 8.8 -fold upregulation. In TGF medium, the two positive chondrogenic markers were significantly upregulated by the fibrin hydrogel. COLIIA1 was significantly increased relative to day 1 , which exhibited approximately 618 -fold through day 28. ACAN transcript values were also significantly upregulated 94-fold over the 28 days of culture. Also, a significant upregulation of COLX was observed. By day 28, COLX levels had increased approximately 68-fold relative to day 1 .

\subsection{Quantification of DNA and GAGs}

A significant decrease in DNA content (weight of DNA/dry weight of sample) among the lyophilized cartilage (CAR), devitalized cartilage matrix, (DCM), and genipin crosslinked cell free scaffold (CF) $(6.99 \pm 0.075,5.72 \pm 0.10$, and $3.77 \pm 0.043 \mu \mathrm{g} / \mathrm{mg}$ respectively) was measured. There was a significant decrease in DNA content between CF scaffolds at day 1 and day 14 (3.77 \pm 0.043 , $2.51 \pm 0.36 \mu \mathrm{g} / \mathrm{mg}$ respectively). However, no significant difference in DNA content between CF scaffolds at day 14 and 28 (2.51 \pm 0.36 , $2.47 \pm 0.35 \mu \mathrm{g} / \mathrm{mg}$ respectively) was observed. At day 14 , there was significant difference in DNA content across medium types in the hybrid scaffolds. The hybrid scaffold group demonstrated an upregulation in DNA content $(1.72 \pm 0.011 \mu \mathrm{g} / \mathrm{mg})$ in response to TGF- $\beta 3$ supplementation compared to the respective control group $(0.83 \pm 0.024 \mu \mathrm{g})$. At day 28 , also TGF- 33 treated scaffolds had significantly higher DNA content $(1.83 \pm 0.263 \mu \mathrm{g} / \mathrm{mg})$ than control group (1.04 $\pm 0.264 \mu \mathrm{g} / \mathrm{mg}$ ) (Fig. $7 \mathrm{~A})$.

There was no significant difference in GAG content (weight of GAG/ weight of DNA) between lyophilized cartilage and DCM, but significant decrease was observed after genipin crosslinking of the scaffolds (78.83 $\pm 3.82,66.96 \pm 5.79$, and $52.78 \pm 0.01 \mu \mathrm{g} / \mathrm{mg}$ respectively).

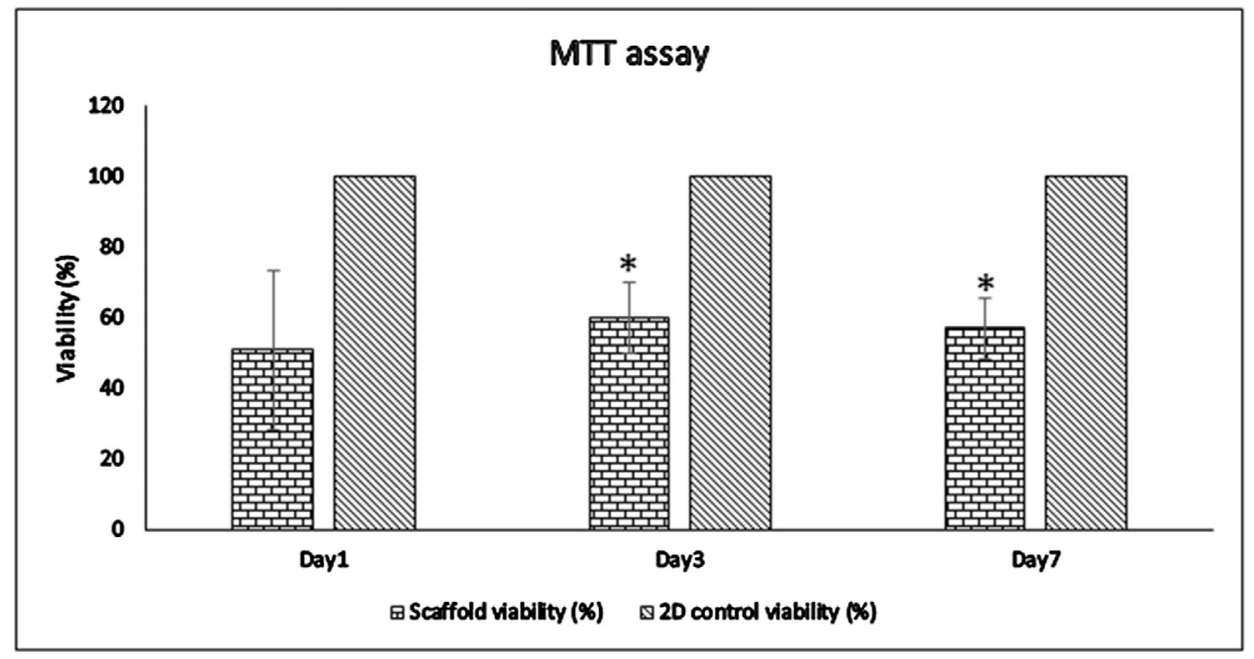

Fig. 5. Comparison of MTT assay results to show viability of ASCs in the (GCDPA70/Fibrin) hybrid constructs in compare with 2D culture plates, used as a control. (Data presented as mean $\pm \mathrm{SD}$, *p $<0.05$ comparing to day $1 ; \mathrm{n}=3$ ). 

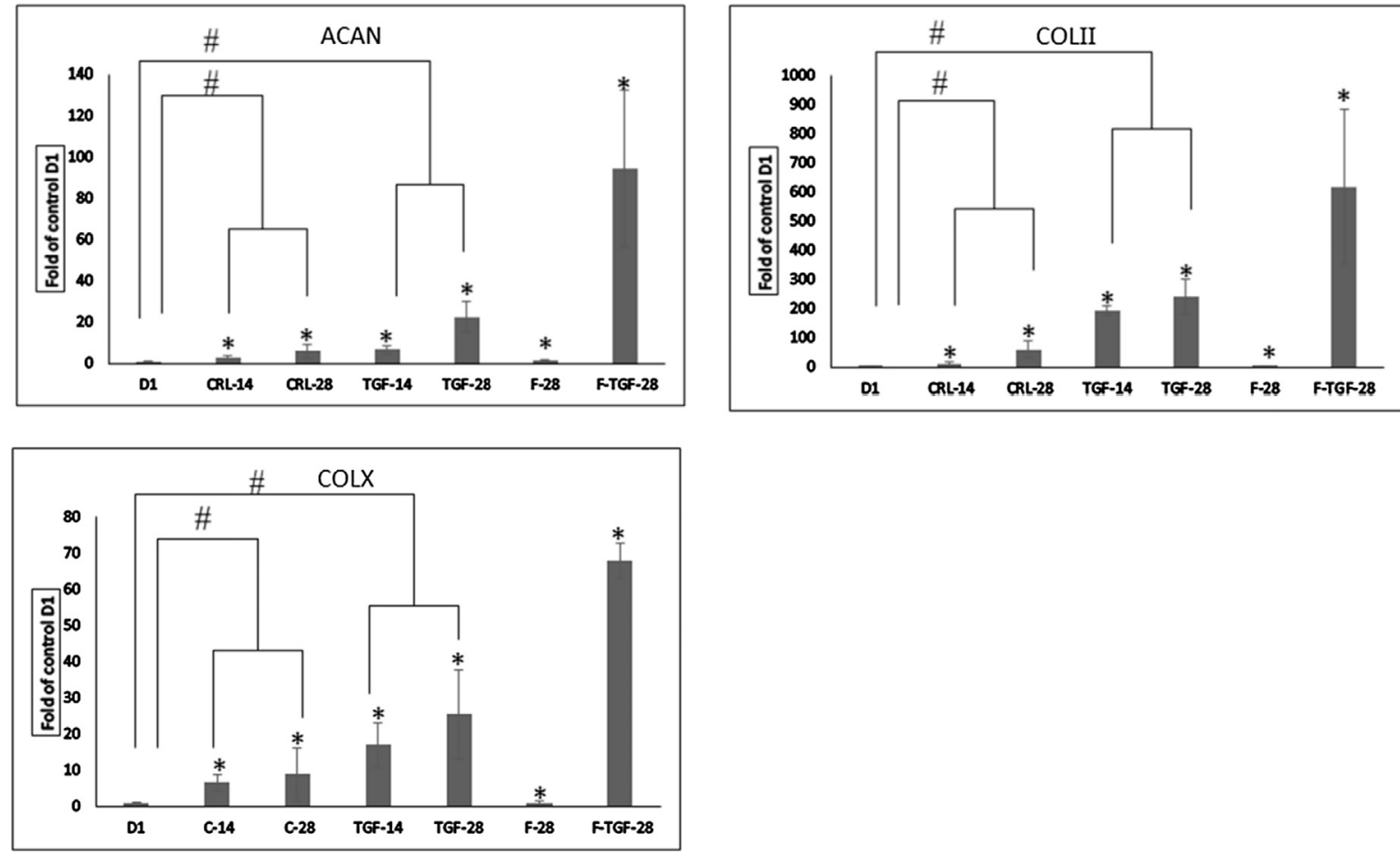

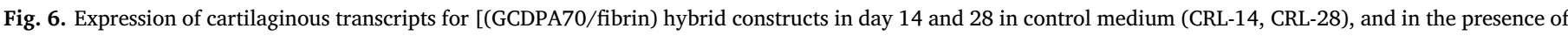

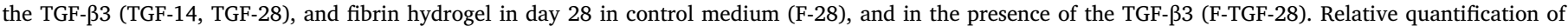

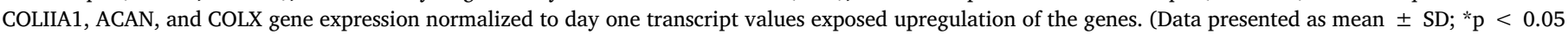
compared to day $1 ; \# \mathrm{p}<0.05$ between the indicated data; $\mathrm{n}=3$ ).

There was a significant decrease in GAG content among the CF scaffolds at day $1, \quad 14$ and $28 \quad(52.78 \pm 0.01,46.92 \pm 7.82$, and $39.87 \pm 6.18 \mu \mathrm{g} / \mathrm{mg}$ respectively). Difference in GAG content among the medium types in the hybrid scaffolds was also observed. The day 14 GAG data displayed a significant increase in GAG content in the hybrid scaffold group in response to TGF- $\beta 3$ supplementation $(54.46 \pm 6.24 \mu \mathrm{g} / \mathrm{mg}) \quad$ compared to the control scaffold $(38.98 \pm 8.82 \mu \mathrm{g} / \mathrm{mg})$. At day 28 , also TGF- $\beta 3$ treated scaffolds had significantly higher GAG content $(63.00 \pm 15.07 \mu \mathrm{g} / \mathrm{mg})$ than the control group (57.00 $\pm 11.15 \mu \mathrm{g} / \mathrm{mg}$ ) (Fig. 7B).

There was a significant decrease in collagen content (weight of hydroxylproline per $10 \mathrm{mg}$ of sample) between lyophilized cartilage and DCM, and also a significant decrease was observed after genipin crosslinking of the scaffolds $(0.162 \pm 0.002,0.158 \pm 0.002$, $0.128 \pm 0.001 \mathrm{mg}$ respectively). At day 1,14 , and 28 , no decrease was observed in collagen content between the CF scaffolds $(0.128 \pm 0.001$, $0.124 \pm 0.001,0.120 \pm 0.003 \mathrm{mg}$ respectively). The hybrid scaffolds exhibited a significant increase in collagen content in the presence of TGF- $\beta 3$ compared to their respective control constructs. Also, at day 14 and 28, TGF- $\beta 3$ treated scaffolds had significantly higher collagen content $(0.049 \pm 0.003$, and $0.056 \pm 0.003 \mathrm{mg}$ respectively) than control groups $(0.004 \pm 0.003$, and $0.01 \pm 0.001 \mathrm{mg}$ respectively) (Fig. 7C).

\subsection{Histology}

Histology of cell-free scaffolds stained via H\&E, toluidine blue, Safranin-O/fast green staining exposed unfilled matrices with big pores. Failure of the pores did not occur in the scaffolds during culture. The cartilage matrix alone stained positively for all staining methods (Fig. 8). In control medium, after 28 day of culture the fibrin hydrogel established minimal matrix production, while hybrid scaffolds exhibited robust newly synthesized matrix that stained positive for GAGs (Fig. 8). In fibrin and hybrid constructs, supplementation with TGF- $\beta 3$ significantly improved the synthesis of new matrix that stained strongly for GAGs, while fibrin hydrogel in micro-mass system exhibited most synthesized matrix compared to hybrid scaffolds. In the hybrid constructs, new matrix deposition was non-uniform and localized to some parts of the scaffolds (Fig. 8). The scaffolds had a higher cell density on the side in which the cells were pipette (Fig. 8).

\section{Discussion}

According to previous studies, synthetic polymers such as PLGA, PLA, PCL, PVA-MA, and PEG have been more frequently used in hybrid scaffolds fabrication. These polymers are biodegradable, biocompatible and their rate of biodegradation can be controlled by the degree of polymerisation, crosslinking, or hybridization with other synthetic and natural biomaterials. To overcome the disadvantage of synthetic polymers, such as their complications in facilitating cell nutrient transfer, hydrophobicity, lack of cell recognition signals and functional adhesion sites, and induction of inflammatory responses, these materials are often modified before cell culture. Therefore, hybrid scaffolds containing both synthetic polymers and ECM derivatives can be considered as a proper strategy for TE applications [6].

The findings of this study demonstrated that only genepin was able to cross-link these two synthetic (PVA) and natural (DCM) components of the scaffolds, among the crosslinking methods that were tested. A novel amine modification approach was performed to enhance crosslinking reactivity of PVA. Genepin crosslinking could prevent cellmediated contraction in the hybrid constructs; a critical characteristic of scaffolds that is essential to maintain for in vivo and in vitro TE applications. Genepin crosslinking produced scaffolds able to support cell attachment and chondrogenic induction of ASCs.

After 28-days of culture, genepin crosslinked scaffolds retained their original shape, while fibrin hydrogels showed contraction throughout in vitro culture. In chondrogenic medium without exogenous growth factors, RT-PCR results combined with histological assessments showed 

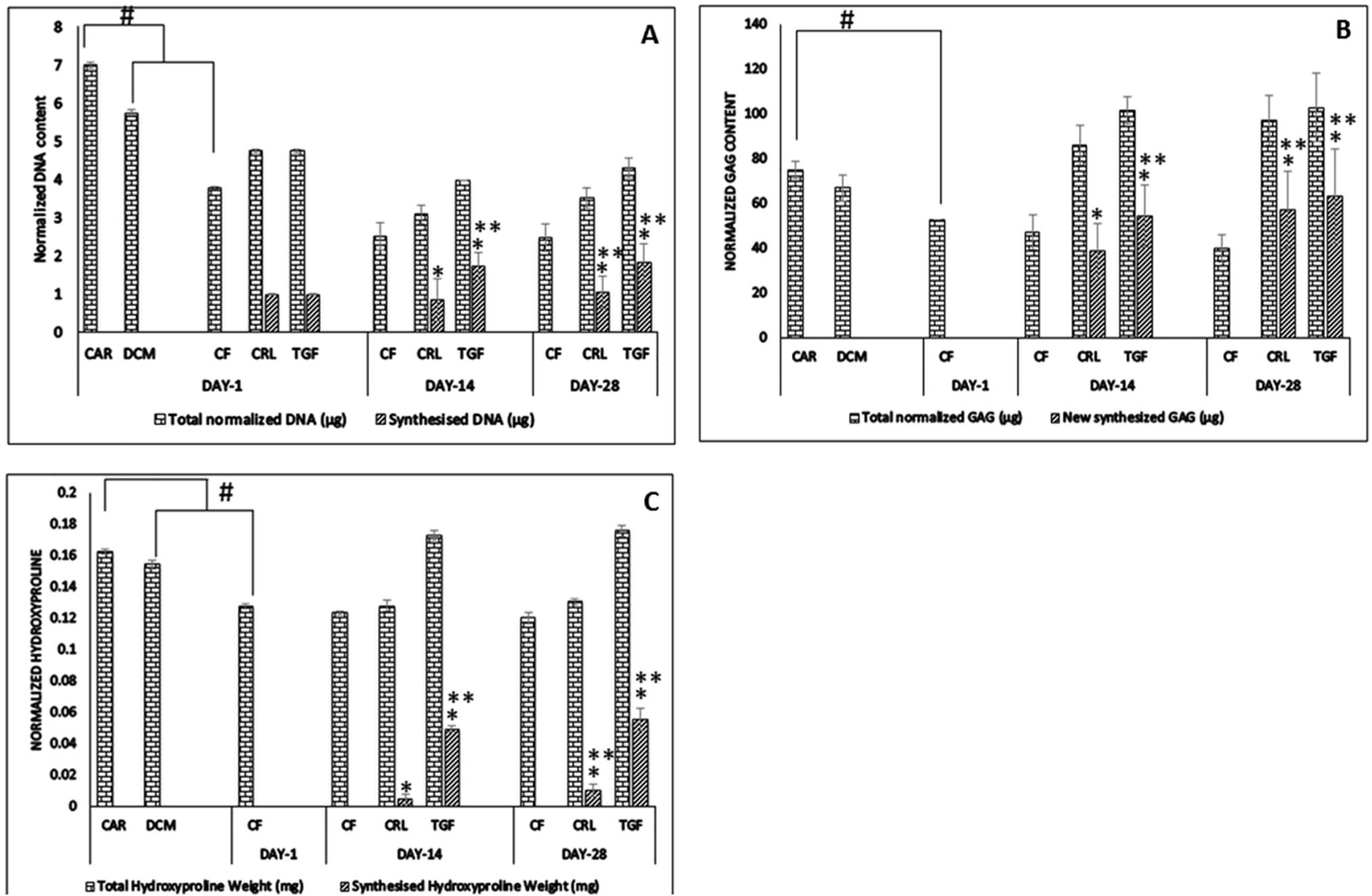

Fig. 7. A: DNA content; B: GAG content; and C: Collagen content of lyophilized cartilage (CAR), devitalized cartilage matrix (DCM), and GCDPA70 cell free scaffold (CF), (GCDPA70/fibrin) hybrid constructs in control medium (CRL), and (GCDPA70/fibrin) hybrid constructs in the presence of TGF- $\beta 3$ (TGF) after 14, and 28 days of culture. All constructs demonstrated increased cellular proliferation, GAG, and collagen contents in the presence of TGF- $\beta 3$ after 14 , and 28 days of culture. (Data presented as mean $\pm \mathrm{SD}$; *p $<0.05$ comparing to the CF scaffolds data of the same day, ${ }^{* *} \mathrm{p}<0.05$ comparing to the CRL-14 group, \#p $<0.05$ between the indicated data; $\mathrm{n}=3$ ).

that during chondrogenic differentiation ASCs synthesized a greater amount of cartilaginous matrix in hybrid scaffolds compared to fibrin hydrogel. In previous studies, many ECM derivatives have been used as scaffolds for TE applications [26,27,49,50]. Other researchers showed that CDM from articular cartilage as a porous scaffold could in part induce chondrogenic differentiation of ASCs without exogenous GFs, showing minimum ECM synthesis from seeded bone marrow derived mesenchymal stem cells (MSC)s [50]. In the present study, human costal cartilage was investigated for its potential chondroinduction ability. In addition, PVA was used as a synthetic biocompatible polymer to conjugate DCM obtained from costal cartilage, to increase biomechanical properties.

In this study, physical crosslinking methods including freeze-thaw cycles, DHT, and UV exposure were performed to conjugate PVA and DCM, but solubility tests showed that none of these methods weren't efficient to crosslink the scaffolds. In a previous study, a PVA solution (16 wt\%, Mw 146,000-186,000) hydrogel combined with articular cartilage derived matrix was crosslinked via freeze-thaw cycles to fabricate porous scaffolds. The goal of this study was to combine PVA mechanical strength with ECM biological features [72]. The difference with our results could be due to the difference in $\mathrm{Mw}$ and concentration of the used polymers. Also, DHT by heating scaffolds in a dry environment at $120^{\circ} \mathrm{C}$ for $24 \mathrm{hrs}$, and UV light exposure at an energy concentration of $8 \mathrm{~J} / \mathrm{cm} 2$ from a $254 \mathrm{~nm}$ source for $80 \mathrm{~min}$ (UV) [50] was performed to crosslink CDM scaffolds. Nevertheless, these methods weren't efficient to crosslink DCM/PVA composite scaffolds investigated in the present study.

(PVA)-chondroitin sulfate (CS) hydrogels were also studied after being crosslinked using glutaraldehyde. CS contained in the scaffolds enhanced Baby hamster kidney (BHK) cell growth and attachment between cells and hydrogels. Moreover, the strength of PVA provided scaffolds with mechanical properties proper to use as a material in TE [55]. In present study, an adequate amount of the genipin solution was added to the DCM/PVA slurry directly, to crosslink the materials and form a hydrogel. The solubility results demonstrated that $0.04 \% \mathrm{wt} / \mathrm{wt}$ genipin was not efficient to crosslink DCM/PVA mixture, while aminemodified PVA crosslinked perfectly in a similar condition. In a previous study, scaffolds composed of cartilage powder were incubated in different genipin solutions to fabricate CDM scaffolds, and a $0.05 \%$ genipin solution supported ASCs proliferation and differentiation, and also prevented cell-mediated scaffold contraction [49].

Between three different (DCM/PVA-A) compositions, (70:30) mixture showed minimum shrinkage and maximum porosity percentage similar to non-crosslinked scaffolds, so we considered this ratio as the best composition for further characterization and cell studies. The average pore diameter of the non-crosslinked and genipin-crosslinked scaffolds was $67 \pm 22$ and $57 \pm 21 \mu \mathrm{m}$, respectively, and the porosity was $89 \pm 3 \%$. According to a previous work, CDM scaffolds crosslinked with high concentration of genipin had similar pore size and porosity to the non-crosslinked scaffolds $(174.9 \pm 5.3 \mu \mathrm{m})$, while scaffolds treated by lower concentration showed significant reduction in pore size $(107.0 \pm 3.6 \mu \mathrm{m})$. Also, the porosities were between 94.7\% and 95.9\% [49]. Another research group fabricated macroporous PVA scaffolds with an average pore diameter of $15.7 \mu \mathrm{m}$, a pore size range $8-304 \mu \mathrm{m}$, and apparent porosity $81 \pm 5 \%$ [73]. Moreover, Stecco et al. fabricated PVA and (PVA/Articular cartilage derived matrix (ACDM)) scaffolds, which presented a rather homogenous porous structure with a pore size ranging from 4 to $10 \mu \mathrm{m}$ [72]. In the present 

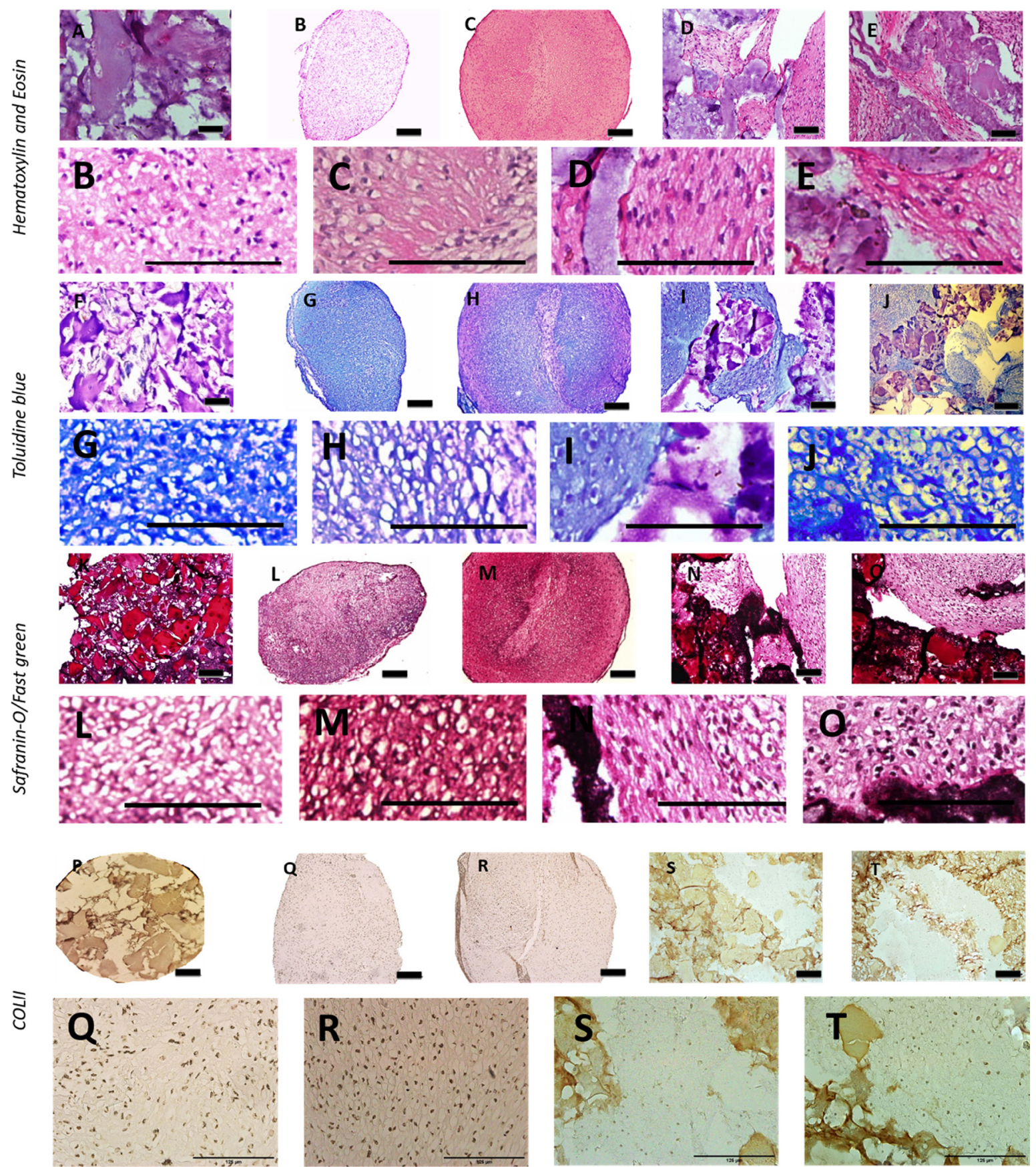

Fig. 8. Chondrogenesis in fibrin/micro-mass culture and hybrid scaffolds. Cartilaginous constructs formed by ASCs cultured under control and TGF mediums. Hematoxylin and eosin (A, B, C, D, E), Toluidine blue (F, G, H, I, J), Safranin-O/fast green (K, L, M, N, O) staining, and Immunoreactivity for COLII (P, Q, R, S, T) after 28 days culture. General morphology, demonstrating a central core surrounded by a basophil transition zoon staining with H\&E, metachromatic staining with TB, and red staining with Safranin-O- are typical of cartilage phenotype. The cell free constructs showed porous structures after culture period. After 28-day culture, abundant synthesized neomatrix was observed in the groups of the fibrin and hybrid constructs in the present of TGF- $\beta 3$. Hybrid construct presented more cartilage like neomatrix compared to the fibrin hydrogel in control medium (scale bar $=125 \mu \mathrm{m}$ ). (For interpretation of the references to colour in this figure legend, the reader is referred to the web version of this article.)

study, the average pore size was smaller compared to the CDM scaffolds investigated by Cheng et al. [49]; while the fabricated GCDPA70 composite scaffolds exhibited a significant bigger pore size than PVA scaffolds reviewed in the previous studies [73]. Scaffolds' pore size and shape play a key role in chondrogenic differentiation, and can partly account for the differential activities of ASCs in the scaffolds $[49,74,75]$. However, the incorporation of the DCM particles in PVA network using amine modification and consequently genipin crosslinking could modulate pore size and shape compared to PVA and PVA/ ACDM scaffolds investigated in previous studies.

The biomechanical behavior of tissue-engineered constructs is a critical outcome for functional TE [76]. The findings of a previous study on ASC-seeded CDM constructs suggested it is likely that the engineered tissue will need to be reinforced to attain functional biomechanical 
properties [77], while the value of elastic modulus of healthy articular cartilage reported in previous studies is in the range from 130 to $573 \mathrm{kPa}$ [78-80]. In the present study, compressive tests demonstrated that reinforcement of the DCM with PVA-A and crosslinking by genipin (0.04\%) exhibited a compression modulus of the hybrid construct to $14.7 \pm 2.2 \mathrm{kPa}$. Compressive aggregate modulus of the genipin crosslinked CDM scaffolds investigated in a previous study were ranged from 55 and $89 \mathrm{kPa}$ [49]. Moreover, the results of the unconfined compressive testing found that $10 \% \mathrm{wt}$ PVA scaffolds possessed a Young's modulus of $15.09 \pm 1.97 \mathrm{kPa}$ at $30 \%$ strain [53]. The resulted GCDPA70 constructs showed very close value of elastic modulus compared to the scaffolds based on PVA and CDM.

The results of the MTT assay showed an increase in cell viability at days 3 and 7 compared to day 1, which suggested that GCDPA70 scaffolds were cell compatible after cross-linking, consistent with previous reports. Previous studies have reported very low cytotoxicity of genipin. Furthermore, ASCs seeded on the genipin-crosslinked CDM scaffolds showed comparable proliferative capability with respect to the non-crosslinked CDM scaffolds [49].

In the present study, gene transcript levels on day 28 for ACAN, COLII A1, and COLX, were upregulated in fibrin hydrogels and genipincrosslinked hybrid scaffolds in both CRL and TGF groups compared to ASCs at day 1. Significant upregulation of COLIIA1 in the fibrin-TGF group compared to scaffold-TGF group was also observed. Reversely, in CRL medium, the gene transcript levels of COLIIA1 in the scaffold-CRL group compared to fibrin-CRL group showed significant upregulation. The observed results suggested that the DCM did not lose its chondrogenic potential after crosslinking with genipin, and provide support for the chondroinduction ability of the hybrid scaffolds. On the other hand, the remaining endogenous active biomolecules in the scaffolds might also effect the chondrogenic differentiation of the ASCs. Similar to what observed in our study, Cheng et al. reported that ACAN and COLII A1 gene transcript levels were significantly upregulated on day 14 in genipin-crosslinked CDM scaffolds for MSCs [49].

Histological and immunohistochemical sections in all TGF- $\beta 3$ treated samples showed the expression of both GAGs and COLII macromolecules. The ASCs-fibrin micro-mass hydrogels appeared more homogenously and uniformly stained for GAGs and COLII compared to hybrid constructs. Similarly, Cheng et al. showed that GAGs and COLII appeared more homogeneous in the non-crosslinked compared to genipin-treated CDM groups [49]. Fibrin hydrogels treated with TGF- $\beta 3$ showed a higher synthesis of both GAGs and COLII matrices compared to hybrid scaffolds. However, it is essential to mention that, the TGF- $\beta 3$ treated ASC-fibrin group produced a hypertrophic phenotype as shown by COLX gene upregulation and according to histological staining (Fig. 8), while COLII dominated the composition. Since ASC-seeded hybrid scaffolds treated by TGF- $\beta 3$ induced synthesis of the COLII and minimized a hypertrophic phenotype, ASCs responded to signals generated from the DCM to differentiate towards a more hyaline chondrocyte phenotype. Proper stimuli to induce rapid tissue remodeling is necessary to induce collagen biosynthesis [81]. As observed in this study, via proper ASCs stimulation from the hybrid scaffolds and TGF$\beta 3$, COLII biosynthesis was significantly induced in a 28-days culture period.

At day 14 and 28, TGF- $\beta 3$ treated scaffolds had significantly higher DNA content than the control medium (Fig. 7) that was according to the results of a previous study performed by Rowland et al. [50]. At day 28, CRL group demonstrated an upregulation in DNA content (Fig. 7). Rowland et al. showed that the CDM scaffolds fabricated via physical crosslinking methods in the presence of TGF- $\beta 3$ exhibited a significant decrease in GAG content, because of GAG release from the scaffolds in the culture medium [50]. In our study, at day 14 cell free scaffolds showed no significant difference in GAG content, but at day 28 there was a significant decrease in GAG content across the medium (Fig. 7), which could have happened due to the scaffold biodegradation. The hybrid constructs treated with TGF- $\beta 3$ had a higher GAG content compared to CRL medium samples (Fig. 7). Similarly, the results of the previous work of Cheng et al. showed that genipin-crosslinked CDM exhibited a significant increases in normalized GAG content at day 28 [49]. Rowland et al. also observed that the non-crosslinked CDM scaffolds exhibited a significant decrease in collagen content compared to crosslinked constructs across the different culture media [50]. In the present study, at day 14 and 28 cell free crosslinked scaffolds showed no difference in COL content across the medium, consistent with previous reports. The hybrid constructs treated with TGF- $\beta 3$ presented higher COL content compared to CRL medium samples at days 14 and 28 (Fig. 7).

Contraction of scaffolds in vivo can generate a gap among the engineered construct and the native surrounding tissue, and could result in the dislodgement of the implanted construct. A recent study showed that the properties of genipin-crosslinked chitosan/COL scaffolds could be greatly affected by various genipin concentrations [82]. In addition, Cheng et al. showed that non-crosslinked CDM scaffolds showed significant construct contraction, while increasing genipin concentration resulted in almost no volume decrease over 28 days' culture period [49]. In addition, the influence of crosslinking on contraction of the scaffold and chondrogenesis in a COLII-GAG scaffolds was explored by Vickers et al. [27]. However, they found that chondrogenicity was inversely related to the crosslinking density of the COLII-GAG scaffolds. Their hypothesis was that prevention of cell-mediated contraction might have eventually restricted chondrogenesis in the scaffolds [27]. Reversely, Cheng et al. showed that CDM scaffolds with 50\% crosslinking density successfully permitted ASCs proliferation and chondrogenesis similar to the non-crosslinked CDM. They elaborated that the endogenous factors and biomolecules could distinguish CDM natural scaffolds from COLII-GAG synthetic scaffolds investigated in the Vickers study $[27,49]$. However, in the present study, fabricated hybrid scaffolds represented completely different behaviors in CRL and TGF medium compared to fibrin hydrogel in the micro-mass culture system. The results of the RT-PCR and histology demonstrated that the fibrinTGF group showed higher synthesis of both GAGs and COLII matrices compared to the hybrid scaffolds, which was according to the results of the study performed by Vickers et al. [27]. In the CRL medium, results confirmed the significant upregulation of COLII and GAG in the hybrid scaffolds compared to the fibrin hydrogel, which was according to the results of the study performed by Cheng et al. [49]

As the histological images showed, the distribution of the cells within the scaffolds was not uniform as well as in fibrin hydrogels. The use of bioreactors for cell seeding may prove useful in this system to increase uniformity in tissue-engineered constructs, and consequently enhance cell growth and differentiation in GCDPA70scaffolds.

Previous studies have used allogenic costal cartilage to regenerate cartilaginous tissue damages including primary and revision rhinoplasty, orbital floor defects, and microtia by surgical reconstruction. To reduce the risk of disease transmission, gamma $(\gamma)$ irradiation of allogenic cartilage was used without further treatments [22,23]. Moreover, chemical crosslinking of xenogeneic or allogeneic ECM scaffolds may elicit an undesired immunogenic response [83]. Therefore, additional in vivo evaluation is necessary to fully recognize the clinical implication of our observations in the present study.

\section{Conclusions}

Generally, beneficial effects of using devitalized cartilage matrix as the constructive material for scaffold fabrication is preservation of the GFs and ability of chondroinduction in the ASCs. The results highlight the importance of the amine-modification of the PVA on crosslinking of the DCM-PVA and reduction of the crosslinker percentage and consequently, minimum contraction and reduction in pore size of the scaffold and improvement of cell-matrix interactions and chondrogenic differentiation of ASCs in scaffolds. Taking into reason the RT-PCR, biochemical, and histological results together, showed that scaffolds 
composed of DCM is able to stimulate ASCs chondrogenesis and also DCM can significantly influence ASC responses to TGF- $\beta 3$ and produced the most required products in terms of increased cellular proliferation, expression of chondrogenic genes, enhanced GAG and collagen synthesis, and reduction of hypertrophic phenotypes compared to fibrin hydrogel. The amine modification of the PVA and consequent crosslinking via genipin could potentially arise from increase mechanical properties, reduction scaffold contraction, which offers bigger pore size suitable for cell proliferation and conservation of cell-matrix interactions in addition to matrix synthesis, that mediate chondrogenic differentiation. Future studies are required to improve cell distribution within the scaffold, and to enhance mechanical properties of the scaffolds and to elucidate specific cell-matrix interactions responsible for mediating chondrogenesis in ASCs.

\section{Declaration of interest}

Authors declare no conflicts of interests.

\section{Acknowledgements}

We would like to thank Dr. Mohammad Kazemi for critical comments on the RT-PCR studies. This work was supported by grants from the Iran University of Medical Sciences, Tehran, Iran.

\section{Appendix A. Supplementary material}

Supplementary data to this article can be found online at https:// doi.org/10.1016/j.eurpolymj.2019.04.044.

\section{References}

[1] A.J. Sutherland, E.C. Beck, S.C. Dennis, G.L. Converse, R.A. Hopkins, C.J. Berkland, M.S. Detamore, Decellularized cartilage may be a chondroinductive material for osteochondral tissue engineering, PloS One 10 (5) (2015) e0121966.

[2] K.A. Athanasiou, E.M. Darling, J.C. Hu, G.D. DuRaine, A.H. Reddi, Articular Cartilage, CRC Press, 2013.

[3] D.J. Huey, J.C. Hu, K.A. Athanasiou, Unlike bone, cartilage regeneration remains elusive, Science 338 (6109) (2012) 917-921.

[4] I. Liao, F.T. Moutos, B.T. Estes, X. Zhao, F. Guilak, Composite three-dimensional woven scaffolds with interpenetrating network hydrogels to create functional synthetic articular cartilage, Adv. Funct. Mater. 23 (47) (2013) 5833-5839.

[5] M.M. Blum, T.C. Ovaert, Low friction hydrogel for articular cartilage repair: evaluation of mechanical and tribological properties in comparison with natural cartilage tissue, Mater. Sci. Eng., C 33 (7) (2013) 4377-4383.

[6] M. Setayeshmehr, E. Esfandiari, M. Rafienia, B. Hashemibeni, A. Taheri-Kafrani, A. Samadikuchaksaraei, D.L. Kaplan, L. Moroni, M. Joghataei, Hybrid and composite scaffolds based on extracellular matrices for cartilage tissue engineering, Tissue Eng. (ja) (2018).

[7] X. He, H. Lu, N. Kawazoe, T. Tateishi, G. Chen, A novel cylinder-type poly (L-lactic acid)-collagen hybrid sponge for cartilage tissue engineering, Tissue Eng. Part C: Meth. 16 (3) (2009) 329-338.

[8] H. Ghasemi Hamidabadi, Z. Rezvani, M. Nazm Bojnordi, H. Shirinzadeh, A.M. Seifalian, M.T. Joghataei, M. Razaghpour, A. Alibakhshi, A. Yazdanpanah, M. Salimi, Chitosan-intercalated montmorillonite/poly (vinyl alcohol) nanofibers as a platform to guide neuronlike differentiation of human dental pulp stem cells, ACS Appl. Mater. Interf. 9 (13) (2017) 11392-11404.

[9] K.L. Spiller, Y. Liu, J.L. Holloway, S.A. Maher, Y. Cao, W. Liu, G. Zhou, A.M. Lowman, A novel method for the direct fabrication of growth factor-loaded microspheres within porous nondegradable hydrogels: controlled release for cartilage tissue engineering, J. Control. Release 157 (1) (2012) 39-45.

[10] C.E. Martin, Super-porous PVA hydrogels with controlled release of IGF-1 for cartilage tissue engineering, Drexel University, 2012.

[11] B. Obradovic, I. Martin, R. Padera, S. Treppo, L. Freed, G. Vunjak-Navakovic, Integration of engineered cartilage, J. Orthop. Res. 19 (6) (2001) 1089-1097.

[12] A.J. Sutherland, G.L. Converse, R.A. Hopkins, M.S. Detamore, The bioactivity of cartilage extracellular matrix in articular cartilage regeneration, Adv. Healthcare Mater. 4 (1) (2015) 29-39.

[13] E.C. Beck, M. Barragan, M.H. Tadros, S.H. Gehrke, M.S. Detamore, Approaching the compressive modulus of articular cartilage with a decellularized cartilage-based hydrogel, Acta Biomater. 38 (2016) 94-105.

[14] C. Vinatier, D. Mrugala, C. Jorgensen, J. Guicheux, D. Noël, Cartilage engineering: a crucial combination of cells, biomaterials and biofactors, Trends Biotechnol. 27 (5) (2009) 307-314.

[15] S. Talakoob, M.T. Joghataei, K. Parivar, M. Bananej, N. Sanadgol, Capability of cartilage extract to in vitro differentiation of rat mesenchymal stem cells (MSCs) to chondrocyte lineage, Int. J. Mol. Cell. Med. 4 (1) (2015) 9.

[16] G.M. Peretti, V. Campo-Ruiz, S. Gonzalez, M.A. Randolph, J. Wei Xu, K.R. Morse, R.E. Roses, M.J. Yaremchuk, Tissue engineered cartilage integration to live and devitalized cartilage: a study by reflectance mode confocal microscopy and standard histology, Connect. Tissue Res. 47 (4) (2006) 190-199.

[17] M.L. Decaris, B.Y. Binder, M.A. Soicher, A. Bhat, J.K. Leach, Cell-derived matrix coatings for polymeric scaffolds, Tissue Eng. Part A 18 (19-20) (2012) 2148-2157.

[18] S. Schwarz, L. Koerber, A.F. Elsaesser, E. Goldberg-Bockhorn, A.M. Seitz, L. Dürselen, A. Ignatius, P. Walther, R. Breiter, N. Rotter, Decellularized cartilage matrix as a novel biomatrix for cartilage tissue-engineering applications, Tissue Eng. Part A 18 (21-22) (2012) 2195-2209.

[19] Z. Yang, Y. Shi, X. Wei, J. He, S. Yang, G. Dickson, J. Tang, J. Xiang, C. Song, G. Li, Fabrication and repair of cartilage defects with a novel acellular cartilage matrix scaffold, Tissue Eng. Part C: Meth. 16 (5) (2009) 865-876.

[20] A.J. Burke, T.D. Wang, T.A. Cook, Irradiated homograft rib cartilage in facial reconstruction, Archives Facial Plastic Surg. 6 (5) (2004) 334-341.

[21] A. Carranza-Bencano, M. Perez-Tinao, P. Ballesteros-Vazquez, J. Armas-Padron, A. Hevia-Alonso, F.M. Crespo, Comparative study of the reconstruction of articular cartilage defects with free costal perichondrial grafts and free tibial periosteal grafts: an experimental study on rabbits, Calcif. Tissue Int. 65 (5) (1999) 402-407.

[22] R.W. Kridel, R.J. Konior, Irradiated cartilage grafts in the nose: a preliminary report, Archives Otolaryngol.-Head Neck Surg. 119 (1) (1993) 24-31.

[23] A. Karimi-Yazdi, M. Sadr-Hosseini, M. Sadeghi, A.-A. Sazgar, R. Safikhani, Comparison of microtia reconstructive surgery with autograft versus homograft, Arch Iran Med. 10 (43) (2007) e7.

[24] Y. Wang, Y.-C. Huang, A.A. Gertzman, L. Xie, A. Nizkorodov, S.L. Hyzy, K. Truncale, R.E. Guldberg, Z. Schwartz, B.D. Boyan, Endogenous regeneration of critical-size chondral defects in immunocompromised rat xiphoid cartilage using decellularized human bone matrix scaffolds, Tissue Eng. Part A 18 (21-22) (2012) 2332-2342.

[25] E.J. Levorson, O. Hu, P.M. Mountziaris, F.K. Kasper, A.G. Mikos, Cell-derived polymer/extracellular matrix composite scaffolds for cartilage regeneration, Part 2: construct devitalization and determination of chondroinductive capacity, Tissue Eng. Part C: Meth. 20 (4) (2013) 358-372.

[26] N.-C. Cheng, B.T. Estes, H.A. Awad, F. Guilak, Chondrogenic differentiation of adipose-derived adult stem cells by a porous scaffold derived from native articular cartilage extracellular matrix, Tissue Eng. Part A 15 (2) (2008) 231-241.

[27] S.M. Vickers, L.S. Squitieri, M. Spector, Effects of cross-linking type II collagen-GAG scaffolds on chondrogenesis in vitro: dynamic pore reduction promotes cartilage formation, Tissue Eng. 12 (5) (2006) 1345-1355.

[28] S.M. Vickers, T. Gotterbarm, M. Spector, Cross-linking affects cellular condensation and chondrogenesis in type II collagen-GAG scaffolds seeded with bone marrowderived mesenchymal stem cells, J. Orthop. Res. 28 (9) (2010) 1184-1192.

[29] A. Bailey, D. Rhodes, C. Cater, Irradiation-induced crosslinking of collagen, Radiat. Res. 22 (4) (1964) 606-621.

[30] K.S. Weadock, E.J. Miller, E.L. Keuffel, M.G. Dunn, Effect of physical crosslinking methods on collagen-fiber durability in proteolytic solutions, J. Biomed. Mater. Res. 32 (2) (1996) 221-226.

[31] H.C. Liang, W.H. Chang, H.F. Liang, M.H. Lee, H.W. Sung, Crosslinking structures of gelatin hydrogels crosslinked with genipin or a water-soluble carbodiimide, J. Appl. Polym. Sci. 91 (6) (2004) 4017-4026.

[32] L.P. Yan, Y.J. Wang, L. Ren, G. Wu, S.G. Caridade, J.B. Fan, L.Y. Wang, P.H. Ji, J.M. Oliveira, J.T. Oliveira, Genipin-cross-linked collagen/chitosan biomimetic scaffolds for articular cartilage tissue engineering applications, J. Biomed. Mater. Res. Part A 95 (2) (2010) 465-475.

[33] M.G. Haugh, M.J. Jaasma, F.J. O'Brien, The effect of dehydrothermal treatment on the mechanical and structural properties of collagen-GAG scaffolds, J. Biomed. Mater. Res. Part A 89 (2) (2009) 363-369.

[34] C.A. Miles, A. Sionkowska, S.L. Hulin, T.J. Sims, N.C. Avery, A.J. Bailey, Identification of an intermediate state in the helix-coil degradation of collagen by ultraviolet light, J. Biol. Chem. 275 (42) (2000) 33014-33020.

[35] C. Lee, A. Grodzinsky, M. Spector, The effects of cross-linking of collagen-glycosaminoglycan scaffolds on compressive stiffness, chondrocyte-mediated contraction, proliferation and biosynthesis, Biomaterials 22 (23) (2001) 3145-3154.

[36] K.G. Cornwell, P. Lei, S.T. Andreadis, G.D. Pins, Crosslinking of discrete self-assembled collagen threads: effects on mechanical strength and cell-matrix interactions, J. Biomed. Mater. Res. Part A 80 (2) (2007) 362-371.

[37] J.E. Lee, J.C. Park, Y.S. Hwang, J.K. Kim, J.G. Kim, H. Suh, Characterization of UVirradiated dense/porous collagen membranes: morphology, enzymatic degradation, and mechanical properties, Yonsei Med. J. 42 (2) (2001) 172-179.

[38] S. Yunoki, T. Suzuki, M. Takai, Stabilization of low denaturation temperature collagen from fish by physical cross-linking methods, J. Biosci. Bioeng. 96 (6) (2003) 575-577.

[39] C. Miles, A. Bailey, Thermally labile domains in the collagen molecule, Micron 32 (3) (2001) 325-332.

[40] M. Koide, K. Osaki, J. Konishi, K. Oyamada, T. Katakura, A. Takahashi, K. Yoshizato, A new type of biomaterial for artificial skin: dehydrothermally crosslinked composites of fibrillar and denatured collagens, J. Biomed. Mater. Res. 27 (1) (1993) 79-87.

[41] M. Chaouat, C. Le Visage, W.E. Baille, B. Escoubet, F. Chaubet, M.A. Mateescu, D. Letourneur, A novel cross-linked poly (vinyl alcohol)(PVA) for vascular grafts, Adv. Funct. Mater. 18 (19) (2008) 2855-2861.

[42] H.W. Sung, W.H. Chang, C.Y. Ma, M.H. Lee, Crosslinking of biological tissues using genipin and/or carbodiimide, J. Biomed. Mater. Res. Part A 64 (3) (2003) 427-438.

[43] H.-C. Liang, Y. Chang, C.-K. Hsu, M.-H. Lee, H.-W. Sung, Effects of crosslinking degree of an acellular biological tissue on its tissue regeneration pattern, Biomaterials 25 (17) (2004) 3541-3552. 
[44] K.L. Moffat, K.G. Marra, Biodegradable poly (ethylene glycol) hydrogels crosslinked with genipin for tissue engineering applications, J. Biomed. Mater. Res. B Appl. Biomater. 71 (1) (2004) 181-187.

[45] H.W. Sung, R.N. Huang, L.L. Huang, C.C. Tsai, C.T. Chiu, Feasibility study of a natural crosslinking reagent for biological tissue fixation, J. Biomed. Mater. Res. 42 (4) (1998) 560-567.

[46] H.-J. Koo, Y.S. Song, H.-J. Kim, Y.-H. Lee, S.-M. Hong, S.-J. Kim, B.-C. Kim, C. Jin, C.-J. Lim, E.-H. Park, Antiinflammatory effects of genipin, an active principle of gardenia, Eur. J. Pharmacol. 495 (2) (2004) 201-208.

[47] M. Ferretti, K.G. Marra, K. Kobayashi, A.J. Defail, C.R. Chu, Controlled in vivo degradation of genipin crosslinked polyethylene glycol hydrogels within osteochondral defects, Tissue Eng. 12 (9) (2006) 2657-2663.

[48] E.G. Lima, A.R. Tan, T. Tai, K.G. Marra, A. DeFail, G.A. Ateshian, C.T. Hung, Genipin enhances the mechanical properties of tissue-engineered cartilage and protects against inflammatory degradation when used as a medium supplement, J. Biomed. Mater. Res. Part A 91 (3) (2009) 692-700.

[49] N.-C. Cheng, B.T. Estes, T.-H. Young, F. Guilak, Genipin-crosslinked cartilage-derived matrix as a scaffold for human adipose-derived stem cell chondrogenesis, Tissue Eng. Part A 19 (3-4) (2012) 484-496.

[50] C.R. Rowland, D.P. Lennon, A.I. Caplan, F. Guilak, The effects of crosslinking of scaffolds engineered from cartilage ECM on the chondrogenic differentiation of MSCs, Biomaterials 34 (23) (2013) 5802-5812.

[51] A. Heidary Rouchi, A.h. Tavakoli, M. Mahdavi-Mazdeh, Iranian homograft tissue processing, 2016.

[52] B. Nozary, A.h. Tavakoli, M. Mahdavi-Mazdeh, S. Zahra, Assessment of brain death of organ donors in Iran, 2010.

[53] N.W. Garrigues, D. Little, J. Sanchez-Adams, D.S. Ruch, F. Guilak, Electrospun cartilage-derived matrix scaffolds for cartilage tissue engineering, J. Biomed. Mater. Res. Part A 102 (11) (2014) 3998-4008.

[54] M. Rafat, L.S. Rotenstein, J.-O. You, D.T. Auguste, Dual functionalized PVA hydrogels that adhere endothelial cells synergistically, Biomaterials 33 (15) (2012) 3880-3886.

[55] C.-T. Lee, P.-H. Kung, Y.-D. Lee, Preparation of poly (vinyl alcohol)-chondroitin sulfate hydrogel as matrices in tissue engineering, Carbohydr. Polym. 61 (3) (2005) $348-354$.

[56] R. Revati, M.A. Majid, M. Ridzuan, K. Basaruddin, E. Cheng, A. Gibson, In vitro degradation of a 3D porous Pennisetum purpureum/PLA biocomposite scaffold, J. Mech. Behav. Biomed. Mater. 74 (2017) 383-391.

[57] M. Agheb, M. Dinari, M. Rafienia, H. Salehi, Novel electrospun nanofibers of modified gelatin-tyrosine in cartilage tissue engineering, Mater. Sci. Eng., C (2016).

[58] J. Muyonga, C. Cole, K. Duodu, Fourier transform infrared (FTIR) spectroscopic study of acid soluble collagen and gelatin from skins and bones of young and adult Nile perch (Lates niloticus), Food Chem. 86 (3) (2004) 325-332.

[59] P. Gordon, C. Huang, R. Lord, I. Yannas, The far-infrared spectrum of collagen, Macromolecules 7 (6) (1974) 954-956.

[60] S. Jia, L. Liu, W. Pan, G. Meng, C. Duan, L. Zhang, Z. Xiong, J. Liu, Oriented car tilage extracellular matrix-derived scaffold for cartilage tissue engineering, J. Biosci. Bioeng. 113 (5) (2012) 647-653.

[61] B. Hashemibeni, A. Valiani, M. Esmaeli, M. Kazemi, M. Aliakbari, F.G. Iranpour, Comparison of the efficacy of piascledine and transforming growth factor $\beta 1$ on chondrogenic differentiation of human adipose-derived stem cells in fibrin and fibrin-alginate scaffolds, Iranian J. Basic Med. Sci. 21 (2) (2018) 212.

[62] M. Teimouri, B. Hashemibeni, M. Mardani, Comparison of aggrecan gene expression in chondrogenesis of adipose-derived stem cells in pellet and micromass culture systems, Tehran Univ. Med. J. TUMS Publ. 76 (2) (2018) 90-95.

[63] A. Kabiri, E. Esfandiari, B. Hashemibeni, M. Kazemi, M. Mardani, A. Esmaeili, Effects of FGF-2 on human adipose tissue derived adult stem cells morphology and chondrogenesis enhancement in Transwell culture, Biochem. Biophys. Res. Commun. 424 (2) (2012) 234-238.

[64] A. Sarveazad, A. Babahajian, M. Bakhtiari, M. Soleimani, B. Behnam, A. Yari,
A. Akbari, M. Yousefifard, A. Janzadeh, N. Amini, The combined application of human adipose derived stem cells and chondroitinase ABC in treatment of a spinal cord injury model, Neuropeptides 61 (2017) 39-47.

[65] S.H. Yang, C.C. Wu, T.T.F. Shih, P.Q. Chen, F.H. Lin, Three-dimensional culture of human nucleus pulposus cells in fibrin clot: comparisons on cellular proliferation and matrix synthesis with cells in alginate, Artif. Org. 32 (1) (2008) 70-73.

[66] A. Valiani, M. Izadi, H. Bahramian, E. Esfandiari, B. Hashemibeni, Comparison between the effect of kartogenin and TGF 33 on chondrogenesis of human adiposederived stem cells in fibrin scaffold, Bratisl. Lek. Listy 118 (10) (2017) 591-597.

[67] Y.Y. Gong, J.X. Xue, W.J. Zhang, G.D. Zhou, W. Liu, Y. Cao, A sandwich model for engineering cartilage with acellular cartilage sheets and chondrocytes, Biomaterials 32 (9) (2011) 2265-2273.

[68] B. Hashemibeni, S. Razavi, E. Esfandiary, S. Karbasi, M. Mardani, M. Nasresfahani, Induction of chondrogenic differentiation of human adipose-derived stem cells with TGF- $\beta 3$ in pellet culture system, Iran. J. Basic Med. Sci. 11 (1) (2008) 10-17.

[69] H.L. Fermor, S.L. Russell, S. Williams, J. Fisher, E. Ingham, Development and characterisation of a decellularised bovine osteochondral biomaterial for cartilage repair, J. Mater. Sci. - Mater. Med. 26 (5) (2015) 1-11.

[70] R.W. Farndale, C.A. Sayers, A.J. Barrett, A direct spectrophotometric microassay for sulfated glycosaminoglycans in cartilage cultures, Connect. Tissue Res. 9 (4) (1982) $247-248$

[71] C. Edwards, W.D. O'Brien, Modified assay for determination of hydroxyproline in a tissue hydrolyzate, Clin. Chim. Acta 104 (2) (1980) 161-167.

[72] E. Stocco, S. Barbon, D. Dalzoppo, S. Lora, L. Sartore, M. Folin, P.P. Parnigotto, C. Grandi, Tailored PVA/ECM scaffolds for cartilage regeneration, Biomed Res. Int 2014 (2014).

[73] K.W. Ng, P.A. Torzilli, R.F. Warren, S.A. Maher, Characterization of a macroporous polyvinyl alcohol scaffold for the repair of focal articular cartilage defects, J. Tissue Eng. Regener. Med. 8 (2) (2014) 164-168.

[74] S. Yamane, N. Iwasaki, Y. Kasahara, K. Harada, T. Majima, K. Monde, S.I. Nishimura, A. Minami, Effect of pore size on in vitro cartilage formation using chitosan-based hyaluronic acid hybrid polymer fibers, J. Biomed. Mater. Res. Part A 81 (3) (2007) 586-593.

[75] C.G. Jeong, H. Zhang, S.J. Hollister, Three-dimensional poly (1, 8-octanediol-cocitrate) scaffold pore shape and permeability effects on sub-cutaneous in vivo chondrogenesis using primary chondrocytes, Acta Biomater. 7 (2) (2011) 505-514

[76] D.L. Butler, S.A. Goldstein, F. Guilak, Functional tissue engineering: the role of biomechanics, J. Biomech. Eng. 122 (6) (2000) 570-575.

[77] F.T. Moutos, B.T. Estes, F. Guilak, Multifunctional hybrid three-dimensionally woven scaffolds for cartilage tissue engineering, Macromol. Biosci. 10 (11) (2010) $1355-1364$.

[78] A. Vidal-Lesso, E. Ledesma-Orozco, L. Daza-Benítez, R. Lesso-Arroyo, Mechanica characterization of femoral cartilage under unicompartimental osteoarthritis, Ingeniería Mecánica, Tecnología y Desarrollo 4 (6) (2014) 239-246.

[79] K. Athanasiou, M. Rosenwasser, J. Buckwalter, T. Malinin, V. Mow, Interspecies comparisons of in situ intrinsic mechanical properties of distal femoral cartilage, J. Orthop. Res. 9 (3) (1991) 330-340.

[80] E.M. Darling, R.E. Wilusz, M.P. Bolognesi, S. Zauscher, F. Guilak, Spatial mapping of the biomechanical properties of the pericellular matrix of articular cartilage measured in situ via atomic force microscopy, Biophys. J. 98 (12) (2010) $2848-2856$.

[81] K. Ng, J. DeFrancis, L. Kugler, T.-A. Kelly, M. Ho, C. O’Conor, G. Ateshian, C. Hung, Amino acids supply in culture media is not a limiting factor in the matrix synthesis of engineered cartilage tissue, Amino Acids 35 (2) (2008) 433-438.

[82] L. Bi, Z. Cao, Y. Hu, Y. Song, L. Yu, B. Yang, J. Mu, Z. Huang, Y. Han, Effects of different cross-linking conditions on the properties of genipin-cross-linked chitosan/collagen scaffolds for cartilage tissue engineering, J. Mater. Sci. - Mater. Med. 22 (1) (2011) 51-62.

[83] S.F. Badylak, T.W. Gilbert, Immune Response to Biologic Scaffold Materials, Seminars in Immunology, Elsevier, 2008, pp. 109-116. 